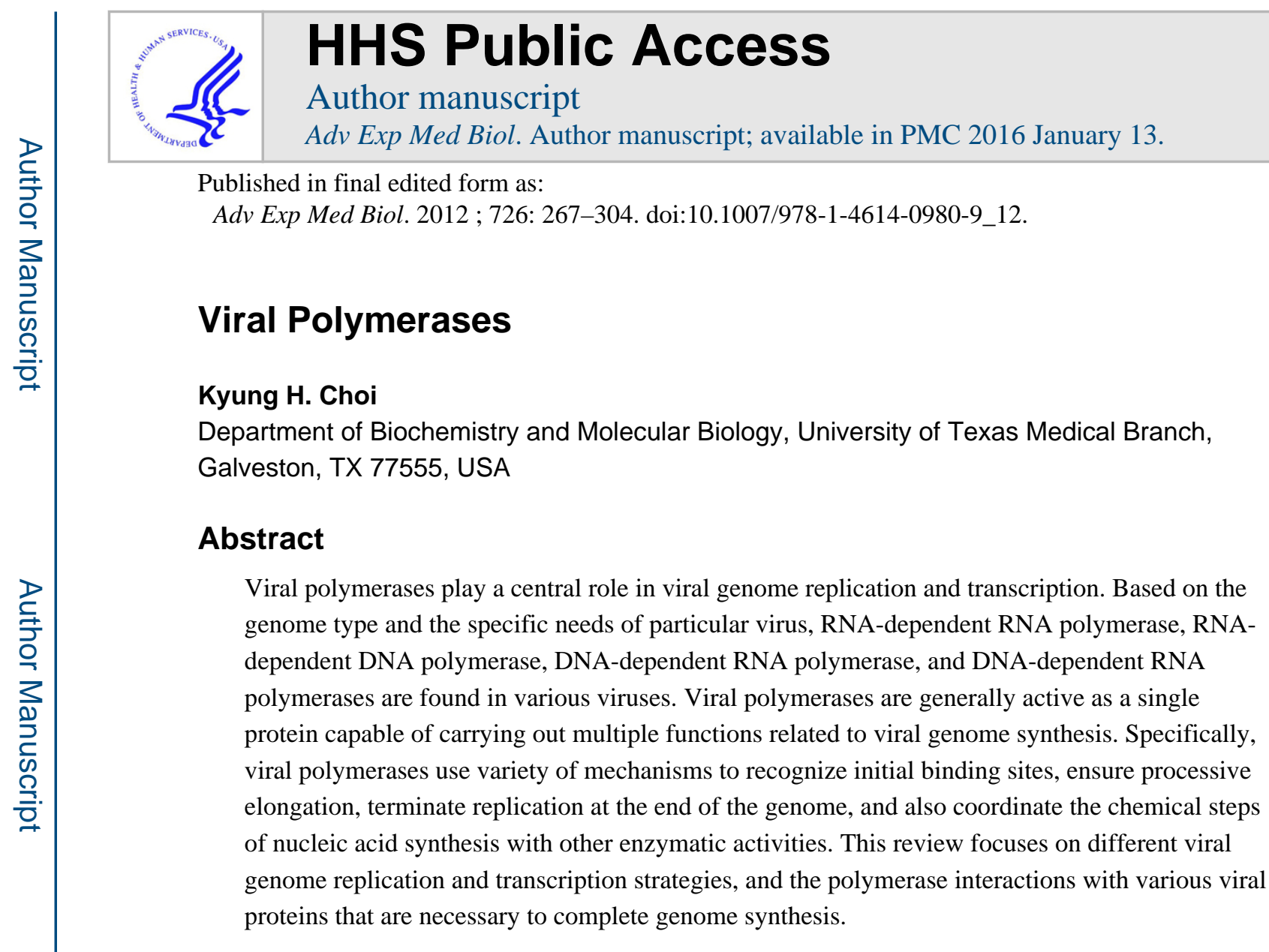

\title{
12.1 Introduction
}

Viral polymerases play a central role in viral genome replication and transcription. Due to the limitations in the genome size that can be packaged in the virus shell, viral polymerases are generally active as a single protein capable of carrying out multiple functions related to viral genome synthesis. Based on genome type and the specific needs of particular virus families, viral polymerases utilize a variety of mechanisms to ensure complete copy of the genome. In particular, they have to recognize initial binding sites, ensure processive elongation, terminate replication at the end of the genome, and also coordinate the chemical steps of nucleic acid synthesis with other modifications of the genome. This chapter focuses on different viral genome replication and transcription strategies and the polymerase interactions with various viral proteins that are necessary to complete genome synthesis.

\subsubsection{Viral Polymerases}

Several steps in the virus life cycle require the activity of a polymerase. Viruses first need to convert their genomes into mRNA that can be translated into viral proteins. Viruses must then synthesize identical copies of their genomes for encapsidation into newly assembled virus capsids. The requirement for a virus-encoded polymerase for either transcription and/or replication depends on the cellular location of genome replication and the nature of the viral genome, i.e., whether it is DNA or RNA, double-stranded or single-stranded, or whether it is plus- or minus-sense. Viruses that spend their entire life cycle in the cytoplasm

K.H. Choi, kychoi@utmb.edu. 
do not have access to host polymerases and thus need to encode their own polymerases for transcription and replication. In contrast, some small DNA viruses that spend their entire life cycle in the nucleus do not need to encode their own polymerase, instead relying entirely on host cell machinery for genome replication and mRNA synthesis. Based on the chemical nature of the viral genome, the need for mRNA synthesis, and the particular genome replication strategy used, viruses are grouped into seven different classes (Baltimore 1971). Figure 12.1 summarizes the seven classes of viruses along with their mode of polymerase usage.

DNA viruses use DNA as their genetic material, which is generally double-stranded (dsDNA) but may also be single-stranded (ssDNA). DNA viruses replicate their genomes using DNA-dependent DNA polymerases (also called DNA polymerases) and transcribe mRNA using DNA-dependent RNA polymerases (also called RNA polymerases). RNA viruses have RNA genomes, which can also be either double-stranded (dsRNA) or singlestranded (ssRNA). Single-stranded RNA genomes can be either plus (+) sense or minus (-) sense. RNA viruses replicate and transcribe their genomes using RNA-dependent RNA polymerases. Reverse-transcribing viruses replicate using reverse transcription, a process for making DNA from RNA templates. Their genomes can be either RNA or DNA.

Retroviruses are ssRNA viruses that replicate through a DNA intermediate, thus requiring a virus-encoded RNA-dependent DNA polymerase (reverse transcriptase). Hepatitis B virus is a dsDNA virus that replicates through an RNA intermediate using a virally encoded reverse transcriptase. Thus, all four possible types of polymerases, i.e., RNA-dependent RNA polymerases, RNA-dependent DNA polymerases, DNA-dependent RNA polymerases, and DNA-dependent DNA polymerases, are found in viruses. RNA-dependent RNA polymerases and reverse transcriptases are unique to viruses since the host cell does not require the RNA replication or reverse transcription.

\subsubsection{Catalytic Mechanism}

The main function of a polymerase is to copy a template nucleic acid strand to produce a daughter strand. Hence, the primary catalytic activity of a polymerase is to transfer a nucleotidyl moiety of an incoming nucleoside triphosphate (NTP) that is complementary to the template strand to the $3^{\prime}$-hydroxyl end of a growing daughter strand of RNA or DNA (Throughout the remainder of the text, NTP refers to either rNTP or dNTP unless specified). Two divalent metal ions, such as $\mathrm{Mg}^{2+}$ or $\mathrm{Mn}^{2+}$, are required for polymerase activity. The polymerase active site thus must have binding sites for a template strand, the DNA or RNA primer terminus (the initiation " $i$ " site), and the incoming NTP (the " $i+1$ " site). The catalytic reaction steps consist of (1) binding of template-primer and NTP, (2) incorporation of nucleoside monophosphate into the growing daughter strand, (3) release of pyrophosphate, and (4) translocation along the template. Upon binding of the template and primer, the correct NTP is incorporated into the daughter strand via Watson-Crick basepairing with the template base (Fig. 12.2). The polymerase active site provides conserved Asp residues that coordinate the two metal ions (either $\mathrm{Mg}^{2+}$ or $\mathrm{Mn}^{2+}$ ). One metal ion, metal ion A in Fig. 12.2, binds the $3^{\prime}$-hydroxyl $\left(3^{\prime}-\mathrm{OH}\right)$ of the terminal RNA or DNA primer at the " $\mathrm{i}$ " site and lowers the $\mathrm{p} K_{\mathrm{a}}$ of the $3^{\prime}-\mathrm{OH}$, thus facilitating nucleophilic attack of $3^{\prime}-\mathrm{O}^{-}$on the a-phosphate of the incoming nucleotide (Steitz 1998). The other metal ion, metal B, binds 
the phosphates of the incoming NTP at the " $\mathrm{i}+1$ " site, positioning the incoming NTP and stabilizing the pyrophosphate leaving group. The 3'-OH of the RNA or DNA primer terminus then attacks the a-phosphate of the NTP, and a new phosphodiester bond is formed with a release of pyrophosphate. Both metal ions would stabilize the charge and geometry of the pentavalent transition state during the nucleotidyl transfer reaction. Upon release of a pyrophosphate product, the newly formed RNA or DNA primer terminus translocates by one base from the $i+1$ site to the $i$ site, and the nucleotidyl transfer reaction is repeated until the template strand is completely copied or a termination signal is encountered.

\subsubsection{Sequence Motifs of Viral Polymerases}

Although overall sequence identity among viral polymerase is very low, even within the same family of viruses, different families of polymerases share a characteristic arrangement of consensus sequences that are involved in binding template, positioning of the priming nucleotide, the nucleotidyl transfer reaction, and maintaining structural integrity of the protein (Poch et al. 1989). These polymerase sequence motifs also provide the basis for identification of new polymerase genes in newly sequenced virus genomes. Conserved sequence motifs have been described for all four types of viral polymerases. RNAdependent RNA polymerases share four major conserved sequence motifs, A, B, C, and D (Fig. 12.3a). Motif A and Motif $\mathrm{C}$ contain the catalytic Asp residues that bind two metal ions in the active site; in particular, motif $\mathrm{C}$ contains the characteristic Gly-Asp-Asp (GDD) sequence embedded in hydrophobic residues. Reverse transcriptases (RNA-dependent DNA polymerases) have five conserved sequence motifs, four of which can be aligned with those from RNA-dependent RNA polymerases. Similar to RNA-dependent RNA polymerases, motifs $\mathrm{A}$ and $\mathrm{C}$ are most strictly conserved.

Viral DNA-dependent RNA and DNA polymerases carry out similar functions to those of the multisubunit polymerases in prokaryotic and eukaryotic organisms and thus share similar sequences. The single subunit DNA-dependent RNA polymerases from bacteriophages T3 and T7 are more closely related to mitochondrial RNA polymerases than to any Escherichia coli (E. coli) polymerases. The multisubunit poxvirus RNA polymerase resembles polymerases from eukaryotic and prokaryotic organisms (Masters et al. 1987). Both DNAdependent RNA polymerases and DNA-dependent DNA polymerases share the three conserved sequence motifs A, B, and C (Delarue et al. 1990). Motif A and C contain the essential Asp residues that bind divalent metal ions necessary for catalytic activity and can be aligned with RNA-dependent polymerase motifs (Fig. 12.3b).

\subsubsection{General Features of Viral Polymerase Structures}

All polymerases have roughly the shape of a "cupped" right hand, consisting of fingers, palm and thumb domains, based on an analogy used to describe the structure of the Klenow fragment of DNA polymerase (Ollis et al. 1985). The palm domain is the most highly conserved domain among different types of polymerases. Most polymerase sequence motifs, including the motifs $\mathrm{A}$ and $\mathrm{C}$, are located in the palm domain. This domain consists of a four- to six-stranded $\beta$-sheet flanked on one side by two a-helices, with the essential Asp residues in motif $C$ located in a hairpin between the two central $\beta$-strands. The fingers and thumb domains vary significantly in both size and secondary structure and reflect the 
specific requirements of replicating single- or double-stranded RNA/DNA genomes. The inner surfaces of the fingers and thumb domains form a template-binding channel that leads into the catalytic palm domain. Template and primer strands bind in the template-binding channel, positioning the primer terminus near the active site (see Figs. 12.6, 12.8, and 12.11). In the active site, the correct NTP to be added to the daughter strand is selected by Watson-Crick base-pairing with the template base. The selectivity of ribose versus deoxyribose NTPs is also provided by the interaction of the polymerase with the $2^{\prime}-\mathrm{OH}$ of the NTP. In general, DNA polymerases that incorporate dNTP in the growing daughter strand have a large side chain that prevents binding of an rNTP with a $2^{\prime}-\mathrm{OH}$. In contrast, RNA polymerases directly interact with the $2^{\prime}-\mathrm{OH}$ of an $\mathrm{rNTP}$ via hydrogen bonding and utilize amino acids with a small side chain to accommodate the $2^{\prime}-\mathrm{OH}$ moiety. The polymerase active site binds the correct NTP with 10-1,000-fold higher affinity than incorrect NTPs (Gao et al. 1997).

In addition to fingers, palm, and thumb domains, viral polymerases often have other domains that carry out functions related to other respects of viral genome transcription and replication. For example, flavivirus RNA-dependent RNA polymerases have a methyltransferase domain that catalyzes methylations of a 5'-RNA cap. Retrovirus reverse transcriptases have an additional ribonuclease $\mathrm{H}$ domain that catalyzes degradation of the RNA strand in the RNA-DNA hybrid during genome replication. Some viral DNAdependent polymerases have a nuclease domain with a proofreading activity to correct nucleotides incorrectly incorporated during genome synthesis. The arrangement of different domains and their functions in viral replication will be discussed in the following sections.

\subsubsection{Polymerase Reaction Steps}

Nucleic acid synthesis by polymerases can be divided into initiation, elongation, and termination phases. Unlike cellular DNA and RNA polymerases, which require oligonucleotides to initiate nucleic acid synthesis, viral polymerases can initiate genome replication using a variety of mechanisms reflecting their adaptation to the host cell.

12.1.5.1 Initiation-All known polymerases synthesize nucleic acid in the $5^{\prime} \rightarrow 3^{\prime}$ direction and thus initiate the nucleoti dyl transfer reaction at the $3^{\prime}$-end of the template strand. Polymerases use one of two initiation mechanisms, either a primer-dependent or a de novo (primer-independent) mechanism (Fig. 12.4). Primer-dependent initiation requires a primer, either in an oligonucleotide or a protein form, which provides the initial $3^{\prime}$-hydroxyl for addition of the first incoming nucleotide. Viral polymerases use one of the four following strategies to initiate nucleic acid synthesis via the primer-dependent mechanism (van Dijk et al. 2004).

1. Oligonucleotide primer. All DNA-dependent DNA polymerases initiate DNA synthesis using a short RNA primer. They can only add new NTPs to the preexisting strand. Reverse transcriptase also uses an RNA primer to initiate DNA synthesis. Some RNA-dependent RNA polymerases synthesize multiple copies of a two to five nucleotide-long RNA that is subsequently used as a primer in the elongation phase. 
2. Cap-snatching. RNA-dependent RNA polymerases from minus-sense RNA viruses use a fragment of cellular-capped mRNA to make viral plus-sense mRNA. These viruses encode an endonuclease that cleaves capped oligonucleotides from the $5^{\prime}$ end of a cellular-capped mRNA and use it as a primer for the minus-sense RNA template. As a result, the viral mRNA contains a $5^{\prime}$-cap and short nontemplated sequences prior to the beginning of a viral transcript sequence (see Sect. 12.2.2).

3. Protein-priming. Similar to the $3^{\prime}$-hydroxyl group of an oligonucleotide primer, a terminal protein can provide a hydroxyl group to which the first nucleotide can be linked via a phosphodiester bond. Viral polymerases catalyze the addition of the first nucleotide to the terminal protein and then use the protein-linked primer for further elongation. As a result, a terminal protein is covalently linked to the $5^{\prime}$-end of the genome. Picornavirus (ssRNA virus), adenoviruses (dsDNA virus), bacteriophage $\varphi 29$ (dsDNA virus), and reverse transcribing hepatitis B virus (dsDNA virus) encode a terminal protein that provides the hydroxyl group from a Tyr or Ser residue for protein priming. The size of terminal proteins varies from small 20 amino-acid peptides in picornavirus to a $30-\mathrm{kDa}$ protein in bacteriophage $\varphi 29$ (see Sects. 2.1.1 and 4.1).

4. Copy-back mechanism. A special case of a primer-dependent RNA initiation is $3^{\prime}$ end elongation by a "copy-back" mechanism, where the 3 '-end of the template folds back upon itself to serve as its own primer. The resulting product is a single chain nucleotide that has twice the length of the template. This type of chain elongation has been observed for recombinant RNA-dependent RNA polymerases from flavivirus (Ackermann and Padmanabhan 2001). However, this is unlikely to be a productive initiation mechanism in infected cells since the doubling of the genome would require a larger protein shell for encapsidation. De novo initiation is the likely mechanism for flavivirus RNA replication in infected cells.

Polymerases can also initiate nucleic acid synthesis without the need of a primer. De novo initiation requires two NTPs, i.e., the initiation NTP at the "i" site and the incoming NTP at the " $i+1$ " site (Fig. 12.2). The initiation NTP provides a 3'-hydroxyl group for the addition of the next nucleotide and thus functions similarly to the $3^{\prime}$-hydroxyl of a primer terminus in a primer-dependent mechanism. Precise initiation at the $3^{\prime}$-terminus of the genome is necessary for preservation of the entire genome sequence. RNA-dependent RNA polymerases from flaviviruses and bacteriophage $\varphi 6$ use a de novo mechanism to initiate RNA synthesis at the 3 -terminus of the template and continue to elongate the entire length of RNA. DNA-dependent RNA polymerases can also initiate RNA synthesis de novo. During the abortive initiation phase, the RNA polymerases initiate RNA synthesis at a promoter DNA sequence and produce short RNA oligonucleotides (3 to 8 nucleotide long). Once the nascent RNA chain becomes approximately nine-nucleotides-long, the polymerase forms a stable elongation complex and synthesizes the entire RNA transcript (see Sect. 12.5.1).

12.1.5.2 Elongation-Once a stable polymerase-nucleic acid complex is formed, the polymerase consecutively adds many nucleotides without dissociation from the template. Most polymerases can add thousands of nucleotides during processive elongation. For 
example, poliovirus RNA-dependent RNA polymerase can add approximately 5,000 nucleotides and 18,000 nucleotides in the absence and presence of its accessory protein $3 \mathrm{AB}$, respectively (Rodriguez-Wells et al. 2001). This indicates that the poliovirus polymerase can synthesize the entire $7.5-\mathrm{kb}$ genome in a single binding event in infected cells. The $\varphi 29$ DNA-dependent DNA polymerase can also synthesize the entire 20-kb DNA genome upon a single binding event without dissociation (Meijer et al. 2001). High processivity requires a stable association of template and primer in the polymerase that prevents dissociation but which should also be nonspecific and weak enough to facilitate movement upon each nucleotidyl transfer reaction steps.

12.1.5.3 Termination-It is poorly understood how viral polymerases terminate nucleic acid synthesis at the $5^{\prime}$-end of the genome. Ending precisely at the $5^{\prime}$-terminus of the genome would be particularly challenging for viruses with linear genomes such as singlestranded RNA or DNA viruses. If the end of the genome is not copied during successive rounds of replication, the genome will become progressively shorter or longer. An exception is DNA-dependent RNA polymerases that terminate RNA transcription at a terminal signal. A newly synthesized RNA forms a GC-rich hairpin followed by a stretch of uridine nucleotides at the terminal signal, and the polymerase-RNA complex is released from the DNA template.

\subsubsection{Polymerases as Molecular Motors}

Polymerases are not only catalytic enzymes but are also mechanical machines that use the energy released from nucleotide transfer to move along the DNA or RNA strand. The movement of the E. coli RNA polymerase along its DNA template has been observed by single-molecule experiments, including microscopy and use of an optical trap to measure force generation during the polymerase reaction. When high mechanical force is applied in opposition to the movement of the polymerase, the rate of replication decreases and finally stops. This "stall" force that is necessary to block the polymerization reaction varies for different polymerases but is in the range of 15-40 pN (Abbondanzieri et al. 2005; Rothwell and Waksman 2005). For example, the force generated by the E. coli RNA polymerase is approximately $20 \mathrm{pN}$, exerting five to six times higher forces than those measured for cytoskeletal motors of myosin or kinesin (Wang et al. 1998; Yin and Steitz 2004). In addition, an optical trap experiment showed that the $E$. coli RNA polymerase translocates along its DNA template in discreet steps of $3.7 \pm 0.6 \AA$. This $3.7 \AA$ step corresponds to the spacing of dsDNA in a B-form helix, indicating that the polymerase moves along the DNA template one base at a time, which had been proposed for all polymerases but never measured (Abbondanzieri et al. 2005).

The mechanism that couples chemical reaction of polymerases to mechanical movement is not known. Two models have been proposed for nucleic acid translocation. In the active "power-stroke" model, the movement is powered by the free energy liberated from phosphodiester bond cleavage, i.e., release of pyrophosphate drives a conformational change that "pushes" the polymerase forward on the template (Yin and Steitz 2004). This model is suggested by structural studies of T7 RNA polymerases in successive steps of nucleotide addition. In brief, the polymerase has the same conformation in both the catalytic NTP 
substrate complex, i.e., prior to the nucleotidyl transfer reaction, and the pyrophosphate product complex, i.e., after the nucleotidyl transfer reaction and prior to pyrophosphate release. This suggests that the nucleotidyl transfer reaction does not require a conformational change in the polymerase and does not promote translocation, and thus, it is likely that the dissociation of pyrophosphate leads to a conformational change that is used to translocate the template-primer (Sect. 12.5.1.3).

Alternatively, in the "Brownian-ratchet" model, or "translocational equilibrium" model, the polymerase oscillates back and forth along the template among number of states that are in equilibrium, including the pre- and posttranslocated states (Guajardo and Sousa 1997). Binding of incoming NTPs stabilizes the posttranslocated state so that at high concentration of NTPs, the translocational equilibrium will favor the posttranslocated state. Binding of NTP acts as a ratchet type of device and prevents back-sliding of the polymerase (Brownianratchet model). Biochemical and single-molecule kinetic studies support the Brownianratchet model and suggest that translocation can be explained in terms of the affinity of NTP and the relative free energies of the polymerase-template-NTP complexes at each step of the polymerase reaction (Abbondanzieri et al. 2005). Whether pyrophosphate release is coupled to a conformational change is a key distinction between the power-stroke and Brownian-ratchet models, and is a question that remains unresolved. Although no conformational changes are involved in the Brownian-ratchet model, it does not exclude a conformational change. Understanding the mechanochemistry of polymerases will require detailed studies on the biochemical, kinetic, and mechanical pathways of the polymerase reaction.

\subsection{RNA-Dependent RNA Polymerase}

\subsubsection{Plus-Sense ssRNA Viruses}

Viruses that possess plus-sense ssRNA genomes include poliovirus and foot-and-mouth virus (Picornaviridae), Norwalk virus (Caliciviridae), Sindbis virus (Togaviridae), and flavivirus (Flaviviridae). RNA genome replication in ssRNA viruses takes place in a membrane-bound replication complex consisting of the viral polymerase and other viral proteins, cellular proteins, and viral RNA. The exact composition and nature of the replication complex is still unknown. Plus-sense genomic RNA serves as an mRNA in infected cells to produce viral proteins without any modification of the viral genome, and thus, viral RNA-dependent RNA polymerases are responsible for replication of the viral RNA genome. The RNA-dependent RNA polymerases first transcribe genomic plus-strand RNA into a complementary minus-strand RNA to form a dsRNA intermediate (Uchil and Satchidanandam 2003). The newly synthesized minus-strand of the dsRNA then serves as a template to generate multiple copies of plus-strand RNA. RNA synthesis occurs in an asymmetric replication cycle in which plus-strand RNA is synthesized in large excess over minus-strand, and all minus-strands exist as a part of the dsRNA intermediate. Viral polymerases copy only virus-specific RNA species in the infected cell, while isolated recombinant polymerases lack specificity and use both viral and nonviral templates for RNA synthesis. Thus, the replication complex may provide selectivity for the viral template by 
concentrating various substrates in the vicinity of the polymerase and thus creating an appropriate environment for selective and efficient genome replication.

Structures of RNA-dependent RNA polymerases have been determined from plus-sense ssRNA and dsRNA viruses. The first structure of an RNA-dependent RNA polymerase was from poliovirus, and several polymerase structures followed in either an unliganded state or complexed with various templates and NTPs (Hansen et al. 1997; Ng et al. 2002; Zamyatkin et al. 2008). A unique feature of the RNA-dependent RNA polymerases is an extensive interaction between the fingers and thumb domains; the fingers domain contains a long insert of several strands, called the "fingertips," that interacts with the thumb domain (Figs. 12.6 and 12.8). The fingertips contribute to formation of a well-defined template-binding channel in the "front" of the polymerase and an NTP channel in the "back" of the polymerase. It was proposed that NTPs would enter the active site through the NTP channel. Because of fingertip-mediated interactions between the fingers and thumb domains, large movements of the thumb domain relative to the fingers domain are restricted, and hence there are no significant conformational changes upon binding of template, primer, or NTP in the template-binding channel in RNA-dependent RNA polymerases. The size of thumb domains vary significantly among RNA-dependent RNA polymerases and seem to play a role in determining whether primer-dependent versus de novo initiation mechanisms are used. Polymerases from Picornaviridae and Caliciviridae that use a primer to initiate nucleotide synthesis have small thumb domains and thus have wider template-binding channels necessary to accommodate both a template and a primer (Fig. 12.6). In contrast, Flaviviridae polymerases that use de novo initiation have large thumb domains and thus have narrower template-binding channels that can accommodate only single-stranded RNA and NTPs (Fig. 12.8).

Viral RNA-dependent RNA polymerases do not have a proofreading nuclease activity, which leads to high rates of misincorporation of nucleotides during genome replication. The mutation rates are estimated to be on the order of one mutation per $10^{3}-10^{7}$ nucleotides, resulting in approximately one error per replicated genome (Drake 1991). In comparison, the mutation rate in E. coli or S. cerevisiae, where cellular polymerases benefit from an errorcorrecting mechanism, is on the order of one mutation per $10^{9}-10^{10}$ nucleotides. Diverse viral genomes resulting from high mutation rates by viral RNA-dependent RNA polymerases may provide an evolutionary advantage for virus survival. For example, mutations in the viral surface protein could lead to new viruses that can evade the host antiviral responses or resist antiviral compounds.

\subsubsection{Picornavirus and Calicivirus Initiate RNA Synthesis via a Primer- Dependent Mechanism-Picornaviridae (poliovirus, foot-and-mouth disease virus} (FMDV), and coxsackievirus) and Caliciviridae (rabbit hemorrhagic disease virus and Norwalk virus) initiate RNA synthesis via a primer-dependent mechanism. Poliovirus, for example, has a small 7.5-kb ssRNA genome which consists of 5'-nontranslated region (NTR), a single open-reading frame, and a $3^{\prime}$-NTR with a polyadenylated [poly(A)] tail. The 5 '-terminus of the RNA genome is covalently linked to a terminal protein VPg (virion protein genome-linked), a 22-amino acid peptide. The viral RNA-dependent RNA polymerase " $3 \mathrm{D}$ " is synthesized as a $3 \mathrm{CD}$ precursor protein that is cleaved into a protease 
$3 \mathrm{C}$ and a polymerase $3 \mathrm{D}$. The $3 \mathrm{CD}$ precursor protein does not have polymerase activity, and rather, it functions as a protease with cleavage specificity that differs from that of the cleaved $3 \mathrm{C}$ protease. The cleaved viral polymerase 3D catalyzes both the initial attachment VPg to the genome and subsequent elongation to produce a new genomic RNA.

3D polymerase initially catalyzes the uridylation of VPg using the $3^{\prime}$ poly(A) tail as a template (step (i) in Fig. 12.5a). RNA synthesis is initiated at the second nucleotide A rather than the 3 -terminal A of the template and covalently attaches UTP to VPg at a conserved Tyr residue (Tyr3). The hydroxyl group of Tyr3 acts analogously to the free $3^{\prime}$-hydroxyl of the primer terminus and forms a phosphodiester bond with the first UTP to form VPg-pU (Fig. 12.5b). This VPg-pU then "slides back" one base and base-pairs with the 3'-terminal A of the template, and 3D polymerase adds the second UTP to form VPg-pUpU (Paul et al. 2003b). The polymerase then uses the VPg-pUpU as a protein-linked primer and the plusstrand genomic RNA as a template to synthesize the entire length of minus-strand RNA (step (ii) in Fig. 12.5a). Next, the 3D polymerase synthesizes the plus-strand RNA using the VPg-pUpU as a primer and the newly synthesized minus strand as a template (step (iii) in Fig. 12.5a). The VPg-pUpU used for plus-strand RNA synthesis is suggested to be synthesized from a conserved cis-acting replication element (CRE) as a template; CRE is an RNA stem-loop containing a $5^{\prime}$-AAAC-3' sequence in the coding region. It is not clear how the polymerase discriminates between the two types of VPg-pUpU, but mutations in the CRE region prevent the viral genome replication (Murray and Barton 2003; Paul et al. 2003a). The structures of 3D polymerase and its complexes that depict successive steps in viral genome replication are described below.

VPg Uridylation by 3D Polymerase (Initiation): Crystal structures of 3D polymerases from Picornaviridae and Caliciviridae are all similar and have the characteristic features of RNA-dependent RNA polymerases such as fingertips that connect the fingers domain to the thumb domain and well-defined template-binding and NTP channels (Thompson and Peersen 2004). These polymerases have small thumb domains, consisting of only several helices, and thus a large template-binding channel that can accommodate an RNA template and a VPg-linked primer (Fig. 12.6a). Additionally, the 3D polymerases complexed with a template, NTP, and VPg, respectively, are very similar to the unbound polymerase, indicating that there are no large conformational changes or domain movements upon binding of VPg, template-primer or template-primer-NTP.

The polymerase initiation complex of VPg-uridylation could be formed by VPg, template $(\mathrm{rA})_{10}$, UTP, and metal ions $\left(\mathrm{Mg}^{2+}\right.$ and $\left.\mathrm{Mn}^{2+}\right)$. However, crystallization conditions containing this combination of chemicals produced a VPg-pU complex, indicating that the uridylation reaction occurred prior to crystallization (Ferrer-Orta et al. 2006). VPg-pU binds in the template-binding channel with the N terminus of VPg located in the NTP entry channel and the $\mathrm{C}$ terminus directed toward the template-binding channel (Fig. 12.6a, b). The hydroxyl group of VPg Tyr3 is covalently attached to the a-phosphate of UMP in VPg$\mathrm{pU}$ and interacts with a divalent metal ion that binds to the catalytic Asp of the GDD motif (Asp338) in the active site. This arrangement of VPg-pU is similar to that of the primer terminus in the nucleotidyl transfer reaction, indicating that 3D polymerase catalyzes $\mathrm{VPg}$ 
uridylation using the same two-metal mechanism as does the nucleotidyl transfer reaction (Fig. 12.2).

The predominant forms of VPg-linked primers in infected cells are VPg-pU and VPg-pUpU, indicating that VPg-pUpU dissociates from the polymerase active site after VPg uridylation and then reassociates as a protein-linked primer for elongation. If VPg uridylation begins at the $3^{\prime}$ poly(A) tail of the template, then the polymerase may continue nucleotidyl transfer reactions to replicate the entire genome. However, if uridylation begins from the CRE, positioned in the middle of the genome, it needs to dissociate and be transferred to the $3^{\prime}$ end of the minus-strand RNA. It is not clear how 3D polymerase terminates RNA synthesis at VPg-pUpU, how the VPg-pUpU is transferred to the $3^{\prime}$-end of the genome, or whether the reassociated VPg-pUpU would bind the same way as in the VPg uridylation reaction.

Nucleotidyl Transfer Reaction: A general model of nucleotide incorporation is that polymerases catalyze the nucleotidyl transfer reaction using an ordered mechanism. Polymerase first binds a template-primer (step 1), followed by binding of an NTP complementary to the template base (step 2). This polymerase complex is then converted into an activated form, which includes a conformational change from an "open" to a "closed" form that is competent to undergo the chemistry step (step 3). Next, the nucleotidyl transfer reaction occurs (step 4), the pyrophosphate product is released, and template-primer translocates by one base (steps 5 and 6). The 3D polymerase structures have been captured in template-primer, open NTP, and closed NTP complexes (steps 1,2, and 3) and are described below.

1. Template - primer binding. In a FMDV polymerase complex containing a selfcomplementary RNA, the template-primer RNA duplex binds in a right-hand Aform helix in the template-binding channel with the $3^{\prime}$-end of the template exiting the active site through the "front" of the polymerase (Ferrer-Orta et al. 2004) (Fig. 12.6c). The template strand in the RNA duplex interacts predominantly with the fingers domain, while the primer strand interacts at the thumb and palm domains. The template-binding channel accommodates seven nucleotides in the template strand. In the active site, the $3^{\prime}$-hydroxyl of the primer terminus forms a hydrogen bond with the catalytic Asp residue in motif C (Asp338), which also binds to a metal ion. Only one metal ion, metal B in Fig. 12.2, is observed in the active site.

2. NTP binding (open conformation). The template-primer-NTP complex in FMDV polymerase has been captured in an "open" conformation, in which the polymerase structure remains unchanged from the template-primer bound form (Ferrer-Orta et al. 2007). In this conformation, the incoming NTP does not base-pair with the template base at the " $\mathrm{i}+1$ " site although the phosphate group of the incoming NTP binds a metal ion near the essential Asp in motif $\mathrm{C}$ (Asp338) and the $3^{\prime}-\mathrm{OH}$ of the NTP forms a hydrogen bond with the essential Asp in motif A (Asp245) (Fig. 12.6d). This conformation is unable to carry out catalytic nucleotidyl transfer reactions and thus suggests that the elongation complex assembles in a sequential order, i.e., the second metal ion that binds to the $3^{\prime}$-hydroxyl of a primer terminus 
would bind in the polymerase active site only after the incoming NTP is correctly assembled in the active site.

3. NTP binding (closed conformation). An elongation complex from Norwalk virus, containing self-complementary RNA, incoming NTP, $\mathrm{Mg}^{2+}$, and $\mathrm{Mn}^{2+}$, represents a perfectly assembled intermediate poised for the nucleotidyl transfer reaction (Zamyatkin et al. 2008). The binding of the template-primer-NTP complex is accompanied by rotations of the helices in the thumb domain, which provides a binding groove for a primer strand, and the loop containing the motif $\mathrm{B}$ in the fingers domain relative to the template-primer-NTP. In this "closed" form, the incoming NTP forms a Watson-Crick base pair with the template base, and the triphosphate group of the NTP binds two $\mathrm{Mn}^{2+}$ ions in the active site. The essential Asp residues in motif A (Asp242) and in the GDD motif (Asp343 and Asp344) also coordinate the divalent metal ions. The correct incoming NTP to be added to the primer strand also seems to be selected in this step by the interaction of polymerase with the $2^{\prime}$-hydroxyl of the rNTP. The $2^{\prime}$-hydroxyl of the rNTP forms hydrogen bonds with Ser and Asn residues in the motif B (Ser303 and Asn309) in the fingers domain. This interaction is missing in the "open" conformation where the incoming NTP is not correctly assembled for catalysis. Thus, this conformation represents a closed complex trapped immediately prior to chemical catalysis. These open and closed conformations described by polymerase complex structures are subtle changes in the active site and should be distinguished from the global domain rearrangements seen in other types of polymerases.

\subsubsection{Flaviviridae RdRps Initiate RNA Synthesis via a De Novo Mechanism}

-Flaviviridae consists of hepacivirus (hepatitis $\mathrm{C}$ virus), pestivirus (bovine viral diarrhea virus, BVDV), and flavivirus (dengue and West Nile viruses). These viruses have approximately 10-12-kb plus-sense ssRNA genomes, which consists of a $5^{\prime}$-NTR, a single ORF, and a $3^{\prime}$-NTR lacking a poly(A) tail. Unique to flavivirus within Flaviviridae, the 5'end of the viral genome has a cap structure and thus requires additional capping enzymes to carry out genome replication. The single ORF is translated into a polyprotein that is cleaved into individual proteins by cellular and viral proteases. Viral RNA-dependent RNA polymerases are synthesized at the $\mathrm{C}$ terminus of the polyprotein. Flaviviridae RNAdependent RNA polymerases vary in size. The $\sim 60-\mathrm{kDa}$ hepatitis C virus "NS5B" polymerase is the smallest Flaviviridae polymerase and contains only a polymerase domain. Pestivirus "NS5B" polymerase has an additional small $\mathrm{N}$-terminal domain whose function is unknown. Flavivirus "NS5" polymerase consists of an N-terminal methyltransferase domain (residues 1-270) that is involved in RNA cap methylation, and a C-terminal polymerase domain.

RNA-dependent RNA polymerases of Flaviviridae initiate RNA synthesis via a de novo mechanism, in which the second NTP is added directly to the $3^{\prime}$-hydroxyl of the first initiation NTP without the need of a primer. The viral polymerases bind at the $3^{\prime}$-end of the plus-strand genomic RNA and copy an entire genome without dissociation (Fig. 12.7). The newly synthesized, negative-sense RNA then serves as a template for synthesizing multiple copies of plus-sense genomic RNA. De novo initiation has an advantage in genome 
replication in that no additional enzymes are required for synthesizing primers, and RNA synthesis can start at the very end of the genome, ideal for copying the entire length of the genome without loss of information (van Dijk et al. 2004). However, formation of a stable de novo initiation complex is challenging. Polymerases must selectively accommodate template, an initiation NTP, an incoming NTP, and two metal ions with precise positioning, which might require additional cofactors. Flavivirus polymerases require a high concentration of GTP as a cofactor for de novo initiation (Kao et al. 1999; Luo et al. 2000). Although de novo initiation is the likely mechanism of genome replication in infected cells, recombinant viral polymerases are capable of RNA synthesis via both de novo and primerdependent initiation mechanisms.

De Novo Initiation by Flavivirus Polymerases: Structures of the polymerase domains from all three members of the Flaviviridae family have been determined (Ago et al. 1999; Bressanelli et al. 1999; Lesburg et al. 1999; Choi et al. 2004; Malet et al. 2007; Yap et al. 2007). Compared to the RNA-dependent RNA polymerases from Picornaviridae or Caliciviridae, all three polymerases possess a large thumb domain and a C-terminal motif within the same domain that encircles the active site (Fig. 12.8a). The larger thumb domain reduces the size of the template-binding channel. The $\mathrm{C}$-terminal motif in the thumb domain (a $\beta$-hairpin in hepatitis $C$ virus NS5B, a $\beta$-strand and connecting loop in pestivirus NS5B, and a loop in flavivirus NS5) occludes the active site and further reduces the size of the template-binding channel. This arrangement of the thumb domain restricts access to the template-binding channel, thus allowing only single-stranded RNA to access the active site during de novo initiation. When the C-terminal motif ( $\beta$-hairpin) is replaced with a shorter turn in hepatitis $\mathrm{C}$ virus NS5B polymerase, the template-binding channel widens, and the mutant polymerase is able to use a dsRNA template-primer complex for a primer-dependent initiation, which wild-type polymerase is unable to use (Hong et al. 2001). Hence, the thumb domain and the $\mathrm{C}$-terminal motif play a role in discriminating between de novo and primerdependent initiation mechanisms.

A high concentration of GTP (but not any other nucleotide) is required for de novo initiation of RNA synthesis in all three members of the Flaviviridae family, regardless of the nucleotide at the $3^{\prime}$-end of the RNA template (Kao et al. 1999; Luo et al. 2000). The role of GTP has been proposed to stabilize the initiation NTP in the de novo initiation complex. The BVDV polymerase, complexed with GTP, shows that GTP binds $6 \AA$ away from the catalytic GDD motif inside the template-binding channel and interacts with residues from all three polymerase domains (Choi et al. 2004) (Fig. 12.8a). When the GTP-binding site residues in BVDV polymerase are individually mutated to Ala, their ability to direct de novo RNA synthesis is almost completely abolished, whereas primer-dependent RNA elongation is reduced by only two- to tenfold (Ranjith-Kumar et al. 2002). This suggests that the GTPbinding site is essential for de novo initiation of RNA synthesis. Modeling the de novo initiation complex by superposition of a $\varphi 6$ polymerase-template-NTP complex with the BVDV polymerase-GTP complex suggests that the ribose triphosphate moiety of the GTP would be positioned as might be expected for the " $\mathrm{i}-1$ " site of already synthesized RNA strand (Fig. 12.8b). The $3^{\prime}$-hydroxyl of the GTP ribose is positioned near the $\alpha$ - and $\beta$ phosphates of the initiation NTP at the "i" site. Thus, the GTP molecule may stabilize the 
initiation NTP by helping to position the $3^{\prime}$-hydroxyl of the initiation NTP for nucleophilic attack on the a-phosphate of the incoming nucleotide (Choi et al. 2004). Once the nucleotidyl transfer reaction occurs, the GTP molecule required for stabilizing the initiation NTP would be released from the active site and the template RNA and product RNA translocated by one base (Fig. 12.8c).

Elongation: Currently, there is no structural information available for initiation or elongation complexes that contain template-NTPs or template-primer-NTP. Modeling of template-primer complexes into the active site of Flaviviridae polymerases suggests that the C-terminal motif in the thumb domain and the enclosed active site would block the path of elongating dsRNA. Thus, as the template-product RNA grows following initiation, a conformational change in the thumb domain to an "open" form is required to allow the dsRNA product to exit the active site (Fig. 12.8c). All Flaviviridae polymerases thus far have been crystallized in the closed form, where the template-binding channel is occluded by the C-terminal motif.

Other Functions of Flavivirus Polymerases: Pestivirus and flavivirus polymerases have an additional domain at their $\mathrm{N}$-termini. The BVDV polymerase is approximately 130 residues longer at its $\mathrm{N}$ terminus than the hepatitis $\mathrm{C}$ virus polymerase. The function of this $\mathrm{N}$ terminal domain is not known, and up to 90 residues can be truncated from the polymerase without loss of polymerase activity. However, deletion of first 106 residues causes a 90\% loss of activity, indicating that residues 91-106 of the N-terminal domain may be involved in the polymerase reaction (Lai et al. 1999). The effects of the deletions are similar for both de novo and 3 '-elongative RNA synthesis, and thus, the N-terminal domain may be involved in a step common to both modes of synthesis. The part of the $\mathrm{N}$-terminal region that is ordered in the crystal structure (residues 92-138) folds into a separate domain (Fig. 12.8a). This domain is positioned over the thumb domain, interacting with the fingertips and the fingers domain either from the same polypeptide chain or from the neighboring protein (Choi et al. 2004, 2006). This domain-swapping of the $\mathrm{N}$-terminal domain and its location near the entrance to the template-binding channel suggests an intrinsic movement of the domain that, along with the fingertips, might drive translocation of the template.

Flavivirus NS5 polymerase has an N-terminal 5'-RNA methyltransferase domain that catalyzes methylations of the $\mathrm{N} 7$ position of guanine in the cap and the ribose $2^{\prime}-\mathrm{OH}$ position of the first nucle otide of the RNA (Egloff et al. 2007). Presence of a $5^{\prime}$-RNA methyltransferase and polymerase in a single polypeptide chain suggests that RNA synthesis and 5'-capping might be coupled during the initial stages of RNA elongation. The coupled process differs from an uncoupled one in that the modified RNA is growing and progressively folding, rather than first synthesizing a full-length RNA before initiating the capping reactions ( $\mathrm{Gu}$ and Lima 2005). The coupling of the two processes would be beneficial for genomic replication because capping enzymes would be concentrated near the nascent RNA, and interactions between RNA capping enzymes and the RNA polymerase elongation complex may allosterically influence the activity of other proteins in the replicase complex. Little is known as to how $5^{\prime}$-RNA methyltransferase and polymerase activities are coordinated in genome replication. 


\subsubsection{Minus-Sense ssRNA Virus}

Viruses that possess minus-sense ssRNA genomes include influenza (Orthomyxoviridae), measles and mumps viruses (Paramyxoviridae), hantavirus (Bunyaviridae), rabies virus (Rhabdoviridae), Ebola and Marburg virus (Filoviridae), and borna disease virus (Bornaviridae). Their genomes can be either nonsegmented or segmented. Segmented genomes are viral genomes that are divided into two or more segments of nucleic acid, all of which are then packaged into a single virus particle. For example, the influenza virus genome is divided into eight viral RNA segments, and the arenavirus genome consists of two RNA segments. The viral minus-sense RNA genome cannot be used for protein synthesis and needs first be transcribed into a plus-sense RNA. Host polymerases cannot carry out RNA-dependent RNA polymerization, and thus, viral RNA-dependent RNA polymerases are packaged in the virion along with the genome and carry out both transcription and replication of the genome (Fig. 12.1). The plus-sense mRNA of these viruses contains a cap at 5 -end and an additional 5-15 nontemplated nucleotides, i.e., a heterogeneous sequence prior to the beginning of viral transcript sequence (Plotch et al. 1981; Lelke et al. 2010). Since the virus does not encode capping enzymes, it is believed that the $5^{\prime}$-cap and the nontemplated nucleotides are derived from cellular mRNA via a "cap-snatching" mechanism. During transcription, the viral polymerase binds a cellular mRNA cap and cleaves it 10-15 nucleotides downstream from the $5^{\prime}$-end via an endonuclease activity. The cleaved, capped RNA is then used as a primer for viral mRNA synthesis. This cap-snatching mechanism was first suggested for influenza virus and later for bunyavirus and arenavirus as well (Bishop et al. 1983; Polyak et al. 1995; Morin et al. 2010).

Functional polymerases for minus-sense RNA viruses are either multiprotein or multidomain complexes. Influenza virus polymerase is a heterotrimer consisting of PA, $\mathrm{PB} 1$, and $\mathrm{PB} 2$ proteins, and bunyavirus and arenavirus polymerase is the large "L" protein composed of multiple domains (Fig. 12.9). The N-terminal domain of influenza virus PA protein and the $\mathrm{N}$-terminal domain of bunyavirus and arenavirus $\mathrm{L}$ protein have endonuclease activities that are likely to be involved in the cap-snatching mechanism. The polymerase sequence motifs containing the essential GDD motif are located in PB1 of influenza virus and in the central region of the $\mathrm{L}$ protein. The enzymatic function of the $\mathrm{C}$ terminus of $\mathrm{L}$ protein is unknown. The crystal structures of endonuclease domains have been determined from influenza virus, La Crosse orthobunyavirus (Bunyaviridae), and lymphocytic choriomeningitis virus (Arenaviridae); all possess a common type II nuclease fold, consisting of a mixed $\beta$-sheet with four strands flanked on both sides by several ahelices (Orlowski and Bujnicki 2008; Morin et al. 2010; Reguera et al. 2010). Structures of neither the polymerase domain nor the full-length polymerase are available for polymerases from minus-sense ssRNA viruses. It is likely that the RNA polymerase domain is similar to other RNA-dependent RNA polymerases, but the details of domain arrangements and mechanism of coordinated cap-snatching and RNA transcription reaction await further structural and functional studies. For a detailed description of bunyavirus transcription and replication, please refer to chapter 11 . 


\subsubsection{Double-Stranded RNA Virus}

Viruses with segmented dsRNA genomes include reovirus and rotavirus (Reoviridae), birnavirus (Birnaviridae), and bacteriophage $\varphi 6$ (Cystoviridae). The dsRNA virus genomes are always segmented. Because dsRNA cannot be used as mRNA for transcription and translation by host enzymes, these viruses also bring their own viral polymerases to synthesize mRNA and replicate their genomes. These viral polymerases are located inside the viral capsid and transcribe the packaged segmented dsRNA genomes within the virion.

\subsection{Reverse Transcriptase (RNA-Dependent DNA Polymerase)}

Two types of viruses are known to use reverse-transcription during their life cycle: retrovirus (Retroviridae) and hepatitis B virus (Hepadnaviridae). Although they both carry out the same reaction, i.e., synthesizing DNA from an RNA template, reverse transcriptases from retrovirus and hepatitis B virus are involved in different steps in the viral life cycle (Fig. 12.1). Retrovirus is a ssRNA virus that uses reverse transcriptase to convert its genome into a dsDNA form that can be integrated into the host genome. Once the retroviral genome is integrated into the host's DNA, mRNA synthesis and its translation are carried out by cellular enzymes. Because cellular polymerases are unable to carry out reverse transcription, the retrovirus encapsidates its own reverse transcriptase in the virion. In contrast, hepatitis B virus is a dsDNA virus that replicates through an RNA intermediate rather than a DNA intermediate. Transcription and protein translation are carried out by cellular polymerases. Hepatitis B virus uses reverse transcriptase to synthesize DNA from the progeny RNA that is synthesized by the cellular polymerase.

\subsubsection{Retrovirus Reverse Transcriptase}

The most studied retrovirus is human immunodeficiency virus (HIV). HIV packages two duplicate copies of a 9.2-kb ssRNA genome, reverse transcriptase, integrase, and protease within each viral particle. HIV uses reverse transcriptase to convert the ssRNA genome into a dsDNA that is subsequently incorporated into the host's DNA genome by the integrase. HIV reverse transcriptase consists of polymerase and ribonuclease (RNase) H domains. RNase $\mathrm{H}$ is an endonuclease that hydrolyzes the RNA strand in an RNA-DNA hybrid and generates 5'-phosphate and 3'-hydroxyl ends (Krug and Berger 1989). The RNase H activity is not coordinated with the polymerase activity, and the rate of cleavage is seven to ten times slower than the polymerase synthesis rate (DeStefano et al. 1994; Basu et al. 2008).

Reverse transcriptase first uses the viral genomic RNA as a template and a cellular tRNA as a primer and initiates minus-strand DNA synthesis at the primer $b$ inding site (PBS) near the 5 '-end of the genome (step A in Fig. 12.10) (Sarafianos et al. 2009; Wendeler et al. 2009). During the synthesis of minus-strand DNA, the RNase H cleaves the RNA strand of the resulting RNA-DNA duplex at multiples sites. When the reverse transcriptase reaches the $5^{\prime}$-end of the RNA genome, the minus-strand DNA is transferred and annealed to the repeat "R" region at the $3^{\prime}$-end of the RNA genome; the RNA genome has identical R regions at each end (step B in Fig. 12.10). Reverse transcriptase continues to synthesize the minusstrand DNA resulting in a RNA-DNA hybrid, and RNase $\mathrm{H}$ continues to degrade the viral RNA in the RNA-DNA hybrid. RNase $\mathrm{H}$ is unable to cleave two short purine-rich RNA 
segments, called polypurine tracks (PPT), and the PPT stay bound to the newly synthesized minus-strand DNA. Next, reverse transcriptase synthesizes the plus-strand DNA using the PPT as primers and the minus-strand DNA as a template (step C in Fig. 12.10). The polymerase stops plus-strand DNA synthesis after copying the PBS region from tRNA, and RNase $\mathrm{H}$ cleaves the $3^{\prime}$-end of the tRNA to create a single-stranded PBS region in the plusstrand DNA. This plus-strand PBS is complementary to the minus strand PBS, and the newly synthesized plus-strand DNA is transferred and annealed to the minus strand PBS (step D in Fig. 12.10). Viral DNA synthesis continues via bidirectional DNA synthesis through the circular intermediate to generate a dsDNA form of the viral genome (step $E$ in Fig. 12.10). The dsDNA is subsequently inserted into the host DNA genome by an integrase in the host cell nucleus, and the viral genome (called provirus) is replicated and transcribed as part of the host's DNA.

The complexity of the retrovirus replication strategy is due to the requirement of synthesizing a DNA that can produce viral RNA genome during transcription in the host. Because the cellular RNA polymerases require a promoter DNA sequence for initiation that is not copied into the RNA transcript, some information in DNA will not be copied to mRNA during transcription. To overcome this problem, retrovirus copies their promoter sequences and transfers them to the opposite ends during reverse transcription. The resulting DNA is thus longer than the RNA template and has identical sequences in both ends. Thus, even if the promoter sequences are lost during transcription, the newly synthesized RNA would be identical to the original RNA genome.

12.3.1.1 DNA Synthesis by Reverse Transcriptase-Reverse transcriptase is synthesized from the "pol" gene product as a 66-kDa protein (p66) that forms a homodimer. P66 is organized as an N-terminal reverse transcriptase domain, a connection domain, and a $\mathrm{C}$-terminal RNase $\mathrm{H}$ domain. The viral protease subsequently cleaves the $66-\mathrm{kDa}$ homodimer and removes the RNase $\mathrm{H}$ domain from one monomer, making a heterodimer consisting of a 66-kDa protein (p66) and a 51-kDa protein (p51) (Kohlstaedt et al. 1992). Only p66 is active as a polymerase and an RNase H. Structures of the p66-p51 heterodimer explain why polymerase activity is observed only for p66 (Fig. 12.11a). Although the individual domains of p66 and p51 subunits are very similar to each other, the arrangements of domains are significantly different between the p66 and p51 subunits. P66 polymerase has the classical fingers, palm, and thumb domain configuration where the template-binding channel is formed by internal surfaces of all three domains. The connection and RNase $\mathrm{H}$ domains of p66 are positioned away from the template-binding channel. In contrast, the polymerase domain of $\mathrm{p} 51$ does not have a template-binding channel. The connection domain occupies the space between the palm and thumb domains and thus blocks the access to the active site residues, making p51 inactive as a polymerase.

Several steps in the nucleotidyl transfer reaction have been captured by structural studies. Binding of nucleic acid or an inhibitor in the polymerase induces a large movement of the thumb domain in respect to the fingers domain (Kohlstaedt and Steitz 1992; Rodgers et al. 1995). In unbound polymerase, the thumb domain contacts a portion of the fingers domain, which "opens" as much as $34^{\circ}$ in relation to the fingers domain to accommodate the template-primer duplex in the polymerase complexes (Fig. 12.11a). This is in contrast to 
RNA-dependent RNA polymerases, where the fingertips in the fingers domain interact extensively with the thumb domain.

Reverse transcriptase, complexed with dsDNA or a PPT-containing RNA-DNA hybrid, shows that the enzyme interacts with nucleic acid through both p66 and p51 domains (Jacobo-Molina et al. 1993; Huang et al. 1998; Sarafianos et al. 2001). The polymerase and the RNase $\mathrm{H}$ domain of the p66 subunit is arranged such that the p66 polymerase active site binds to the primer terminus, and the RNase $\mathrm{H}$ active site contacts the template-primer duplex 17 nucleotides downstream (Fig. 12.11b). The connecting and thumb domains of p51 form a floor in the nucleic acid binding cleft between the polymerase and RNase $\mathrm{H}$ domains. The dsDNA and RNA-DNA hybrid have an A-form helix near the polymerase active site that gradually becomes B-form near the RNase $\mathrm{H}$ active site. The $\mathrm{p} 66$ polymerase active site binds to a $3^{\prime}$-end of the primer mainly through a $\beta$-hairpin in the palm domain, named a "primer grip." The primer grip orients the $3^{\prime}$-hydroxyl of a primer terminus for nucleophilic attack on the a-phosphate of the incoming NTP. Similarly, template strand binds in the polymerase active site through a "template grip" consisting of residues from the palm and fingers domains (Fig. 12.11b).

An elongation complex of reverse transcriptase containing template, primer, and incoming NTP was obtained by cross-linking the polymerase and template-primer dsDNA and by incorporating dideoxynucleotide at the $3^{\prime}$-end of the primer (Huang et al. 1998). Although the primer terminus lacks the $3^{\prime}$-hydroxyl group and was thus unable to attack the incoming NTP, the deoxyribose is ideally positioned to attack the incoming NTP via its missing $3^{\prime}$ $\mathrm{OH}$. The NTP forms a Watson-Crick base pair with the template base, and the triphosphate group of NTP binds two metal ions that are coordinated by the essential Asp residues in motifs A and C. Compared to the template-primer complex, the binding of the incoming NTP induces a movement of the fingers domain closer to the thumb domain and thus closes down on the NTP binding site.

12.3.1.2 RNA Degradation by RNase H-While minus-strand DNA is synthesized from the RNA template, RNase $\mathrm{H}$ degrades most of the RNA in the RNA-DNA hybrid nonspecifically. In particular, RNase H cleaves 17-18 nucleotides downstream from the polymerase active site (Furfine and Reardon 1991; Basu et al. 2008). As described earlier, the distance between the polymerase and RNase active sites is $\sim 60 \AA$, which corresponds to 17 base pairs for the duplex DNA and 18 base pairs for an RNA-DNA hybrid, consistent with the biochemical data. The RNase $\mathrm{H}$ is proposed to control the cleavage specificity by reducing the width of minor groove and interacting with the DNA primer strand near the RNase $\mathrm{H}$ active site. The RNA-DNA hybrid typically adopts a conformation close to an Aform helix, in which the minor groove is 9-10 $\AA$ on average. RNase $\mathrm{H}$ cleaves substrates with different minor groove widths much less efficiently. In addition, residues near the RNase $\mathrm{H}$ active site, named the "RNase $\mathrm{H}$ primer grip," bind the DNA primer strand four to nine nucleotides downstream to the scissile phosphate base pair (Fig. 12.11b). Mutations of residues in the RNase $\mathrm{H}$ primer grip affect the specificity of RNase $\mathrm{H}$ cleavage in vitro and in vivo, suggesting that the RNase H primer grip might control the specificity of the RNase H (Julias et al. 2002; Rausch et al. 2002). This idea is further supported by a structure of reverse transcriptase bound with PPT-containing RNA-DNA, which is resistant to RNase $\mathrm{H}$ 
cleavage. In this complex, the RNA-DNA hybrid has unpaired and mispaired bases in the PPT region $\left[(\mathrm{rA})_{4}:(\mathrm{dT})_{4}\right]$ and a significantly narrower minor groove of $\sim 7 \AA$, less than the typical 9-10 ̊ groove. Although it is not clear whether this conformation of adenosine-rich PPT is an intrinsic property of the helix, this conformation places the scissile phosphate $\sim 3$ $\AA$ away from the RNase $\mathrm{H}$ active site, thus preventing cleavage.

\subsubsection{Coordination of Multiple Activities in Reverse Transcriptase-During} genome replication, reverse transcriptase catalyzes RNA-dependent DNA synthesis, RNA cleavage in an RNA-DNA hybrid, DNA strand transfer, and DNA-dependent DNA synthesis. Thus, reverse transcriptase has to recognize and orient different primer-template pairs in the active sites of the polymerase and RNase $\mathrm{H}$ domains for appropriate activities. How does reverse transcriptase determine the correct orientation of the polymerase domain or RNase $\mathrm{H}$ domain on the template-primer complex for its activity? Recent singlemolecule fluorescence resonance energy transfer (FRET) measurements suggest that the binding orientation of reverse transcriptase on the template-primer complex determines the enzymatic activity (Abbondanzieri et al. 2008). Specifically, interaction between the primer backbone near the 5'-end of the primer, i.e., DNA versus RNA, and the "RNase H primer grip" determines the binding orientation of reverse transcriptase. When DNA primer binds to the DNA template (which would be the case for plus-sense DNA synthesis from minusstrand DNA), the polymerase domain binds to the $3^{\prime}$-end of the DNA primer, and the RNase $\mathrm{H}$ domain binds near the $5^{\prime}$-end of the primer. This is the correct orientation of the polymerase domain to initiate DNA synthesis. In contrast, when an RNA primer with a random sequence binds to the DNA template (which would be a case for nonspecific cleavage of the RNA template in a RNA-DNA hybrid), the polymerase domain binds to the $5^{\prime}$-end of the RNA primer, and RNase $\mathrm{H}$ domain is close to the $3^{\prime}$-end of the primer. Since the polymerase active site does not bind to the $3^{\prime}$-end of a primer, the polymerase would not elongate the primer. Instead, the RNase H domain would cleave RNA at $18 \mathrm{nt}$ from the 5'end of template. However, when the polypurine PPT-containing RNA is used as a primer (which would be the case for minus-strand DNA synthesis, step C in Fig. 12.10), the reverse transcriptase slides on the template-primer complex, rapidly shuttling between the $3^{\prime}$ - and $5^{\prime}$-ends of the primer, and thus, the polymerase can use PPT as a primer for a DNA synthesis.

\subsubsection{Hepatitis B Virus Reverse Transcriptase}

Hepatitis B virus (hepadna virus) is a dsDNA virus, but its transcription and replication mechanisms are distinct from those of other dsDNA viruses. The 3.2-kb genome of hepatitis B is a mostly double-stranded circular DNA, but is not covalently closed, and is thus termed a relaxed circular DNA (rcDNA). The minus-sense DNA strand is a genome-length, and the viral polymerase "P" protein is covalently linked at its 5 '-end. The plus-sense DNA strand is variable in length but generally shorter than the full-length genome and has an RNA primer attached at the 5'-end (Nassal 2008; Sohn et al. 2009). Upon entry into cells, the genomic DNA is transported to the nucleus and converted into a plasmid-like covalently closed circular DNA (cccDNA) by cellular enzymes. Subgenomic RNA is then synthesized from the cccDNA by cellular RNA polymerase II. One of the subgenomic RNAs, called the pregenomic RNA (pgRNA), has a full viral DNA sequence and is encapsidated into the viral 
capsid with the polymerase "P" protein. Only a single pgRNA and a single P protein are packaged per particle. Inside the capsid, plus-sense pgRNA is reverse-transcribed to minussense DNA by the P polymerase. During minus-sense DNA synthesis, most pgRNA of the RNA-DNA hybrid is degraded by the RNase $\mathrm{H}$ of the $\mathrm{P}$ protein. The last cleavage by RNase $\mathrm{H}$ occurs $11-16 \mathrm{nt}$ from the $5^{\prime}$-end of pgRNA. The $\mathrm{P}$ polymerase subsequently uses the remaining $~ 15$ RNA nucleotides as a primer and the minus-strand DNA as a template to synthesize plus-sense DNA and generate partially double-stranded rcDNA.

The $90-\mathrm{kDa}$ polymerase $\mathrm{P}$ protein from hepatitis B virus consists of terminal protein, spacer, reverse transcriptase, and RNase H domains (Radziwill et al. 1990). The terminal protein domain ( 180 amino acids) at the $\mathrm{N}$ terminus of $\mathrm{P}$ protein acts as a protein primer, similar to VPg in poliovirus and the terminal protein in bacteriophage $\varphi 29$. Tyr63 provides a hydroxyl group to which the first nucleotide of the minus-sense DNA is added. Because the terminal protein is a part of reverse transcriptase $\mathrm{P}$, the polymerase domain is also covalently linked to the $5^{\prime}$-end of minus-sense DNA. Hepatitis B virus is the only example of a viral polymerase that is covalently attached to the viral genome (Nassal 2008). The next $\sim 150$ amino acids of the spacer region are highly diverse among hepadna viruses, and the majority of the region can be deleted without loss of polymerase activity (Radziwill et al. 1990). Thus, the function of the spacer region is suggested to tether the terminal protein domain at the $\mathrm{N}$ terminus and the $\mathrm{C}$-terminal polymerase domain. Recently, a zinc finger motif has been identified within the spacer region that is critical for pgRNA binding and encapsidation (Kim et al. 2009). The reverse transcriptase domain carries out minus-sense DNA synthesis using pgRNA as a template and the terminal protein as a protein primer. The C-terminal RNase $\mathrm{H}$ domain degrades pgRNA during minus-strand DNA synthesis, similar to RNase $\mathrm{H}$ of retrovirus reverse transcriptase. Currently, no structure is available for any of the hepadna virus reverse transcriptases. Future structural studies of $\mathrm{P}$ protein will help illuminate the strategy that hepadna viruses use for genome transcription and replication.

\subsection{DNA-Dependent DNA Polymerases}

DNA viruses replicate using either host or viral DNA-dependent DNA polymerases, also called DNA polymerases. Viral DNA-dependent DNA polymerases are similar to host DNA polymerases, and some of these virus polymerases even have a proofreading activity. Most DNA viruses have dsDNA genomes that can be in either a linear or circular form. Viruses with linear dsDNA genomes include adenovirus (Adenoviridae), herpesvirus (Herpesviridae), small pox or vaccinia virus (Poxviridae), and tailed bacteriophages such as Q29 and T7 (Podoviridae). Viruses with circular dsDNA genomes include papillomavirus (Papillomaviridae) and polyomavirus (Polyomaviridae). Eukaryotic DNA viruses with small genomes (4-9 kb), such as papillomavirus and polyomavirus, use cellular enzymes in the nucleus for both genome transcription and replication and thus do not encode a viral polymerase (Mesters et al. 2006). In contrast, cytoplasmic DNA viruses with large genomes, which spend most of their life cycles in the cytoplasm, are unable to access host DNA and RNA polymerases and thus encode their own DNA-dependent DNA and RNA polymerases. For example, vaccinia virus (Poxviridae), with an approximately 190-kb-long linear dsDNA genome, encodes its own DNA and RNA polymerase as well as other enzymes that are responsible for replication and the transcription. Since the replication and transcription 
machineries are needed immediately upon infection, they are packaged in viral capsids along with the DNA genome (Broyles 2003).

All DNA-dependent DNA polymerases require a primer for nucleic acid synthesis. Thus, viruses with linear genomes face the challenge of copying the $5^{\prime}$-end of the genome during replication. If the end of the genome is not copied during successive rounds of replication, the genome will become progressively shorter. To overcome this problem, some bacteriophages release a linear genome into the cell that is then converted into a circular form prior to replication or is integrated into the host chromosome (prophage) (Weigel and Seitz 2006). Cellular DNA polymerases can then elongate either the 3'-OH end of nicked dsDNA as a primer using the unnicked strand as a template in a rolling circle mechanism.

\subsection{1 dsDNA Bacteriophage $\phi 29$ DNA-Dependent DNA Polymerase}

Bacteriophages $\varphi 29, \mathrm{Cp}-1, \mathrm{PRD}-1$, and adenovirus have a linear dsDNA genome and use a protein-primed initiation mechanism to copy the very end of the genome (Meijer et al. 2001). Bacillus subtilis phage $\varphi 29$ has a 19.3-kb dsDNA genome with an origin of replication at each end. Both 5'-termini of the dsDNA genome are covalently attached to a terminal protein "gp3." The $\varphi 29$ DNA-dependent DNA polymerase "gp2" initiates DNA synthesis using the terminal protein gp3 as a protein primer via the sliding-back mechanism (Fig. 12.5b). The polymerase begins DNA synthesis at the second $\mathrm{T}$ in the $3^{\prime}$-end of the $\varphi 29$ genome and covalently attaches dATP to the hydroxyl group of a conserved Ser residue of the terminal protein to form a terminal protein (TP)-dAMP link (step A in Fig. 12.12). This TP-dAMP then slides back one base and forms a base pair with the $3^{\prime}$-terminal $\mathrm{T}$ of the template. The polymerase then starts DNA synthesis at the +2 position and elongates the rest of the template (Blanco and Salas 1996; Meijer et al. 2001). Because the gp2 polymerase can initiate DNA synthesis from each terminus of the dsDNA genome, there is no equivalent of lagging strand synthesis seen in cellular DNA polymerases (Blanco and Salas 1996). Instead, the DNA replication intermediate is a dsDNA containing single-stranded DNAs (step B in Fig. 12.12). When two DNA polymerases pass by each other, the templates separate into two duplex DNAs containing one full-length DNA and one shorter DNA (step $\mathrm{C}$ in Fig. 12.12). DNA synthesis continues until the polymerase reaches the $5^{\prime}$-end of the template, resulting in a DNA duplex with terminal proteins at each $5^{\prime}$-end of the genome. The gp2 polymerase also has a DNA helicase activity to unwind duplex DNA (strand separation) and an exonuclease activity to correct misincorporated nucleotides during the DNA replication. In addition to gp2 polymerase and gp3 terminal protein, the replication of Q29 in vitro requires ssDNA binding protein gp5 and dsDNA binding protein gp6. Gp5 binds and protects the single-stranded region of DNA from degradation during replication, and gp6 forms a nucleoprotein complex with the dsDNA genome and helps open the ends of the dsDNA (Blanco and Salas 1996).

12.4.1.1 Protein-Primed Initiation by $\phi 29$ Polymerase-The $\varphi 29$ gp2 polymerase belongs to the B-type superfamily of DNA-dependent DNA polymerases that also includes DNA polymerases of eukaryotic polymerase a and E. coli polymerase II. The gp2 polymerase consists of an N-terminal exonuclease domain (residues 1-189) and a Cterminal DNA polymerase domain (190-575). The exonuclease domain catalyzes $3^{\prime} \rightarrow 5^{\prime}$ 
cleavage of a single-stranded DNA and is responsible for the proofreading activity. In addition to the classical fingers, palm, and thumb domains, the $\varphi 29$ polymerase domain has two insertions in the palm domain called terminal protein regions 1 and 2 (TPR1 and TPR2). The TPR1 and TPR2 are only present in the B-type family of DNA-polymerases that replicate via a protein-priming mechanism (Meijer et al. 2001). TPR1 forms a small domain next to the palm domain and TPR2, together with the thumb domain, forms an arch over the template-binding channel (Fig. 12.13a). The exonuclease domain is positioned between the fingers and thumb domains and encircles the template-binding channel together with the palm, thumb, TPR1, and TPR2 domains. Mutations of residues in TPR1 and TPR2 greatly reduce protein-primed DNA synthesis and exonuclease activities, consistent with the observed structure (Dufour et al. 2003).

The structure of the terminal protein-priming initiation complex consisting of $\varphi 29$ DNA polymerase and the terminal protein suggests how the large terminal protein is used to initiate DNA synthesis (Kamtekar et al. 2006). The terminal protein consists of three domains, the $\mathrm{N}$-terminal (residues 1-73), the intermediate (74-172), and the C-terminal priming domains (173-266) (Fig. 12.13b). The intermediate and priming domains interact with the TPR1 and TPR2 of the polymerase, respectively. In particular, the priming domain of the terminal protein binds in the template-binding channel, positioning the priming loop containing the conserved Ser required for initiation (Ser232) near the catalytic site of polymerase. Unfortunately, the density for Ser232 is not observed in the structure, suggesting that the priming loop might be flexible without a template strand. The interaction between the priming domain and polymerase is mostly electrostatic, similar to the interaction of the template-primer complex in the polymerase active site. The priming domain occupies the most of the template-binding channel, and thus, only a short template could bind in the channel during the initiation of DNA synthesis. The first addition of dATP to the terminal protein requires precise positioning of the template terminus, dATP, and terminal protein in the polymerase active site. By excluding most of the volume in the template-binding channel, the terminal protein could provide specific interaction with the template terminus to form a stable initiation complex. As the template and protein-linked primer extend, the priming domain of the terminal protein would move out of the templatebinding channel to accommodate the longer template-primer duplex.

The terminal protein has high affinity $(80 \mathrm{nM})$ for polymerase even in the absence of nucleic acid but dissociates from the polymerase after synthesis of six to ten nucleotides (Lazaro et al. 1995; Mendez et al. 1997). Modeling of template-primer in the polymerase active site suggests that the intermediate domain of terminal protein could maintain the interaction with TPR1 of the polymerase, while the priming domain is pushed out of the template-binding channel at each addition up to six or seven nucleotides (Kamtekar et al. 2006). The terminal protein would dissociate from the polymerase after seven nucleotide synthesis steps, consistent with the biochemical data. The release of the terminal protein from the polymerase would trigger a transition from the initiation to the elongation phase in which a stable template-primer DNA complex is formed, and DNA synthesis proceeds with high processivity. 
12.4.1.2 Elongation-DNA-dependent DNA polymerases are highly processive, and the $\varphi 29$ polymerase can synthesize the entire 20-kb DNA genome in a single binding event without dissociation (Meijer et al. 2001). High processivity requires a tight polymeraseDNA interaction to prevent dissociation but also should allow relative movements between the polymerase and template at each step of the polymerization. The $\varphi 29$-type DNA polymerases accomplish this by treading the template DNA under a tunnel, which would prevent the dissociation of the template DNA from the polymerase during translocation and nucleotide addition steps. The structure of the $\varphi 29$ polymerase complexed with a DNA duplex shows that the duplex region of the template-primer is encircled by the thumb domain and TPR2 (Fig. 12.13c) (Berman et al. 2007). The $5^{\prime}$-end single-stranded template is threaded under the "downstream template tunnel" formed from the exonuclease domain, TPR2, palm, and fingers domain. The downstream template tunnel is only large enough to accommodate single-stranded DNA and may play a role in strand separation. Deletion of TPR2, which forms an arch over the template-binding channel, reduces processivity and strand separation of the mutant enzyme, consistent with the model (Rodriguez et al. 2005; Kamtekar et al. 2006).

The overall polymerase structure is similar among unbound, terminal protein complex, template-primer complex, and template-primer-NTP complexes, and there is no large movement of domains. However, one distinctive difference between the template-primer complex and the template-primer-NTP complex is that the incoming NTP binding site is occupied by the side chain of a conserved Tyr residue (Tyr254) in the fingers domain in the absence of the incoming NTP (Fig. 12.13d top). Upon binding of incoming NTP to the template-primer, the fingers domain rotates $14^{\circ}$ toward the polymerase active site and "closes" onto the incoming NTP. The Tyr254 which occupies the NTP binding site in the absence of incoming NTP now rotates to stack on the incoming dNTP (Fig. 12.13d bottom). The dNTP base-pairs with the template base, and the triphosphate moiety interacts with the conserved Lys in motif B (Lys383) and the two metal ions that are coordinated by the catalytic Asp residues in polymerase motif A (Asp249) and C (Asp458).

12.4.1.3 Proofreading by the $\phi 29$ Polymerase-The $\varphi 29$ polymerase contains an exonuclease domain that provides a proofreading activity during DNA synthesis. The RB69 polymerase (a $\varphi 29$-like polymerase) and DNA complex shows that the exonuclease domain contacts only three nucleotides at the $3^{\prime}$-end of the ssDNA, suggesting that primer transfer from the polymerase to the exonuclease active site would require an opening of at least three to four base pairs in template-primer duplex (Hogg et al. 2004). During replication, a primer terminus containing an error will be transferred from the polymerase to the exonuclease active site for cleavage and then be transferred back to the polymerase active site for elongation. The major determinant of this switch coordinating DNA synthesis and degradation has been proposed to be the strength with which the primer terminus binds to the respective active sites. Mutational studies show that a single mutation in a conserved motif (YxGG/A), located between the exonuclease and polymerase domains, results in polymerases that exhibit different ratios of the polymerase activity versus the exonuclease activity due to loss of DNA binding in either the polymerase or the exonuclease active site. For example, the loss of DNA binding in the polymerase active site results in the increased 
activity of the exonuclease (Truniger et al. 1996, 1999). Consistent with this idea, a singlemolecule experiment showed that the mechanical tension between the polymerase and the mismatched DNA duplex promotes the transfer of the primer terminus to the exonuclease active site (Ibarra et al. 2009). Mismatched dsDNA induces a long-range tension on the dsDNA helix, and weakens the binding of the template-primer in the polymerase active site. The polymerase subsequently stalls, which facilitates the transfer of the primer terminus to the exonuclease active site.

\subsubsection{Eukaryotic ssDNA Viruses Do Not Encode a Polymerase Gene}

A small number of eukaryotic viruses are ssDNA viruses that have either linear or circular DNA genomes. Smaller-sized viral genomes indicate a higher dependence of the viral life cycle on the host cellular proteins for transcription and replication of the viral genome. Parvovirus B19 (Parvoviridae) has a small linear ssDNA genome of $\sim 5 \mathrm{~kb}$ in size and does not encode a viral polymerase (Kasamatsu and Nakanishi 1998). In the nucleus, the singlestranded genome is converted into a dsDNA intermediate by host DNA polymerases. This dsDNA is used for both transcription and replication of the genome. Host DNA polymerases synthesize more plus- and minus-sense ssDNA by a rolling-circle mechanism. Either form can be encapsidated into the viral capsid.

\subsection{DNA-Dependent RNA Polymerase}

Viral DNA-dependent RNA polymerases share similar functions and specificities with cellular RNA polymerases. Many DNA viruses rely on cellular RNA polymerases for transcription and therefore carry out part of their infection cycle in the nucleus. An exception is cytoplasmic dsDNA viruses, which carry out viral transcription in the cytoplasm, and thus encode DNA-dependent RNA polymerases. DNA-dependent RNA polymerases are different from DNA-dependent DNA polymerases in that they bind at a specific promoter duplex DNA sequence to initiate RNA synthesis, and they are able to carry out de novo synthesis without a primer. The newly synthesized RNA is generally released from the DNA template, and thus, the double-stranded DNA helix is maintained except for a short region called a transcription bubble within which a transient DNA-RNA hybrid is formed. DNA-dependent RNA polymerases also exhibit a distinct transition from initiation to elongation. Following the initial RNA synthesis, RNA polymerases release many short $(<10)$ nucleotides that failed to be converted into a full-length transcript (abortive initiation). Only after the polymerase synthesizes $\sim 10$ nucleotides does the polymerase begin processive elongation.

\subsection{1 dsDNA Bacteriophage T7 DNA-Dependent RNA Polymerase}

Bacteriophage T7 has a linear dsDNA genome of $\sim 40 \mathrm{~kb}$ in size. The T7 DNA-dependent RNA polymerase is related to the mitochondrial RNA polymerases. Unlike multisubunit cellular RNA polymerases, the T7 RNA polymerase is a single-subunit protein and performs the complete transcription cycle without any additional proteins. Thus, it has been used as a model system to study multisubunit RNA polymerases. The T7 RNA polymerase is extremely promoter-specific and only transcribes the DNA downstream of a 17 base-pair T7 promoter. The polymerase first binds at a promoter site and separates the dsDNA into single 
strands (Fig. 12.14). The coding strand then serves as a template for the RNA synthesis. While bound at the promoter sequence, the $\mathrm{T} 7$ polymerase first undergoes abortive initiation, where the polymerase synthesizes and releases many short (three to eight nucleotide-long) RNA transcripts from the polymerase-promoter complex (step A in Fig. 12. 14). When the nascent RNA transcript reaches eight to nine nucleotides, the RNA stably associates with the transcription complex, and the polymerase proceeds to synthesize the entire RNA transcript until it reaches a termination signal (step B in Fig. 12. 14). When the polymerase reaches the termination signal, it stops, and the polymerase and the RNA transcript dissociate from the dsDNA template (step C in Fig. 12. 14).

12.5.1.1 Promoter Recognition and Abortive Initiation-T7 RNA polymerase consists of an $\mathrm{N}$-terminal domain $(35 \mathrm{kDa}$ ) unique to DNA-dependent RNA polymerases and a C-terminal polymerase domain $(60 \mathrm{kDa})$ that is homologous to the E. coli DNA polymerase I (pol I) family of polymerases (Jeruzalmi and Steitz 1998). The N-terminal domain, positioned in front of the polymerase, interacts with the palm and thumb domains and partially occludes the polymerase active site (Fig. 12.15a) (Sousa et al. 1993; Cheetham and Steitz 1999; Tahirov et al. 2002). The T7 polymerase initiation complex, containing a three-nucleotide RNA transcript, shows the structural basis for specific recognition of the promoter DNA and abortive initiation. The T7 polymerase initiation complex was produced by addition of a 17 base-pair promoter DNA duplex, which contains a single-stranded region at the $5^{\prime}$-end, and a three-nucleotide RNA that can base-pair with the ssDNA region (Cheetham and Steitz 1999). In the crystal structure of the initiation complex, the polymerase separated the -4 to -1 region of the promoter DNA duplex near the RNA synthesis initiation site ( +1 site) to form a transcription bubble. The +1 to +3 sites of the single-stranded DNA template base-pair with the RNA transcript in an A-form helix in the active site (Fig. 12.15a). The promoter DNA binds mainly to the N-terminal domain and a $\beta$ hairpin (residues 739-770) in the fingers domain, named the "specificity loop"; the Nterminal domain binds the duplex region $(-17$ to -5$)$ of the promoter sequence, while the specificity loop interacts with the major groove of the promoter DNA in a sequence-specific manner.

DNA protection and cross-linking experiments suggest that the initiation complex of T7 RNA polymerase accommodates up to eight base pairs of the DNA-RNA hybrid in the polymerase active site while bound in the promoter site (Temiakov et al. 2000). However, the T7 initiation complex shows that the template-binding channel is just large enough to accommodate three to four base pairs, and a DNA-RNA hybrid longer than four base pairs would clash with the $\mathrm{N}$-terminal domain. This apparent discrepancy suggests that the existence of additional conformations of the polymerase initiation complex that would accommodate longer RNA transcripts. Recent structural studies show one such intermediate, where the promoter binding site rotates along with the bound promoter DNA to incorporate a longer DNA-RNA hybrid in the active site (Durniak et al. 2008). Thus, transition from initiation to elongation requires successive conformational changes in the $\mathrm{N}$-terminal domain. Many of these intermediate conformations are not faithful, leading to abortive initiations. 
12.5.1.2 Processive Elongation-When the nascent RNA transcript reaches eight to nine nucleotides, the polymerase releases the promoter DNA and starts synthesizing downstream DNA sequences. T7 RNA polymerase is highly processive and can synthesize 200 nucleotides per second and the entire 40-kb genome within minutes (Golomb and Chamberline 1974). DNA-dependent RNA polymerases require specific interaction with the promoter in the initiation phase but need high processivity and nonspecific DNA interactions in the elongation phase. How does the T7 RNA polymerase accomplish these seemingly exclusive tasks? T7 RNA polymerase undergoes structural reorganization that removes the promoter binding site in the N-terminal domain and encircles the RNA transcript in a tunnel that prevents dissociation of DNA-RNA hybrid from the polymerase.

A T7 RNA polymerase elongation complex was obtained using a duplex DNA containing 11 noncomplementary bases in the middle to mimic a transcription bubble, and a ten-nucleotide RNA that would base-pair with the coding DNA strand in the transcription bubble (Yin and Steitz 2002). Among the ten-nucleotide RNA, seven nucleotides at the 3 '-end RNA basepair with the template DNA in the active site, and the other three nucleotides are separated from the template strand, exiting the polymerase active site (Fig. 12.15b). Compared to the initiation complex, the polymerase undergoes a major rearrangement of the $\mathrm{N}$-terminal domain and the specificity loop in the elongation phase. The N-terminal domain, which forms a part of the promoter binding site in the initiation complex, now forms a part of the "RNA transcript exit tunnel" together with the thumb domain and the specificity loop (Fig. 12.15b). In particular, residues $160-190$ in the N-terminal domain move approximately $70 \AA$ from the bottom to the top of the thumb domain and form a helix-turn-helix. This refolded region of the N-terminal domain, named "subdomain H," or "flap," creates binding sites for the 5'-end of the RNA on one side and the single-stranded nontemplate DNA on the other. These structural changes result in a larger template-binding channel that can accommodate up to five to eight base pairs of DNA-RNA duplex. The specificity loop, which makes sequence-specific interactions with the promoter DNA in the initiation complex, also moves away from the template-binding channel to open space in the RNA exit tunnel. The RNA exit tunnel would thread an RNA transcript that is longer than eight nucleotides, consistent with the transition to elongation at $\sim 8$ nucleotides derived by biochemical studies. Similar to the TPR2 in $\varphi 29$ DNA polymerases (Fig. 12.13c) and the sliding clamp of DNA replication, T7 RNA polymerase threads the RNA transcript through an RNA exit tunnel created in the elongation complex, making the DNA-RNA hybrid unable to dissociate from the polymerase.

\subsubsection{Nucleotidyl Transfer Cycle in DNA-Dependent RNA Polymerases-The} structures of the T7 polymerase have been determined in successive steps of nucleotidyl transfer cycle including (1) template-primer binding (posttranslocated state), (2) NTP binding in noncatalytic site ("open" template-primer-NTP complex), (3) NTP binding in a catalytic site ("closed" template-primer-NTP complex), and (4) pyrophosphate binding (pretranslocated state). After pyrophosphate is released and translocation occurs, the polymerases cycle back to the template-primer binding state (Yin and Steitz 2004).

1. Template-primer binding (posttranslocated state). Template and primer bind in the template-binding channel, and the primer terminus near the catalytic metal binding 
sites (Fig. 12.16; (i)). In the absence of the incoming NTP, the side chain of a conserved Tyr in the fingers domain (Tyr639) occupies the NTP binding site and stacks with the base at the primer terminus. This configuration would sterically block binding of an incoming NTP. In addition, the template nucleotide at the " $\mathrm{i}+$ 1 " site (that would base-pair with incoming NTP) "flips out" to a position that is incapable of forming a base pair with the incoming NTP. It has been suggested that this template-binding site could function as a "ratchet" to prevent a template strand slippage, until the correct NTP is assembled in the active site. As mentioned earlier, Q29 DNA polymerase also has a similar Tyr residue occupying the incoming NTP binding site in the absence of NTP (Fig. 12.13d).

2. NTP binding in the noncatalytic site ("open" form). The incoming NTP binds in a noncatalytic ("pre-insertion") site that is incapable of participating in a nucleotidyl transfer reaction (Fig. 12.16; (ii)). This T7 polymerase complex is formed by an addition of a noncleavable $\alpha, \beta$-methylene ATP (in which an oxygen that links $\alpha$ and $\beta$-phosphate in ATP is replaced with a methyl group) to the template-primer. The template nucleotide at the " $\mathrm{i}+1$ " site is still in a "flipped-out" position that is not competent to form a base pair with incoming NTP. The NTP binding site is partially occupied by Tyr639. Although the ATP analog does not base-pair with the template base at the " $\mathrm{i}+1$ " site, the phosphate moiety of the ATP analog binds near the catalytic Asp residues in motif $\mathrm{C}$ and interacts with the basic residues in the ahelix in the fingers domain (Arg627 and Lys631) that also contains Tyr639 at the distal end. This mode of binding has not been described in $\varphi 29$ DNA polymerase.

3. NTP binding in the catalytic site ("closed" form). The incoming NTP, the template at the " $i+1$ " site, and the primer terminus are ideally positioned for nucleotidyl transfer (Fig. 12.16; (iii)). This T7 polymerase complex, also formed by addition of an $a, \beta$-methylene ATP, shows that the template nucleotide at the $i+1$ site now binds in a position that is expected for the nucleotidyl transfer reaction. The adenosine moiety of $\alpha, \beta$-methylene ATP forms a base pair with the template nucleotide thymidine at the " $i+1$ " site, and the triphosphate moiety binds two catalytic metal ions that are coordinated by the catalytic Asp residues in polymerase motifs A and C (Asp537 and Asp811). Compared to the templateprimer complex or the template-primer-ATP analog complex bound in the noncatalytic site, the a-helix in the fingers domain that contains Tyr639, Arg627, and Lys631 rotates approximately $20^{\circ}$ to interact with correctly bound incoming NTP. In this "closed" form, the triphosphate of the ATP analog maintains interactions with basic residues Arg627 and Lys631. The correct incoming NTP to be added to the primer strand would be selected in this step by the interaction of polymerase with the $2^{\prime}-\mathrm{OH}$ of the rNTP.

4. Catalysis and product release (pretranslocated state). This is the conformation following chemical catalysis but prior to pyrophosphate product release (Fig. 12.16; (iv)). The T7 RNA polymerase-pyrophosphate complex is formed by addition of $3^{\prime}$-deoxyATP and pyrophosphate. The structure shows that the $3^{\prime}$ deoxyATP has been added to the growing RNA and that the pyrophosphate moiety binds where the $\beta$ - and $\gamma$-phosphate of the catalytic NTP bind. The pyrophosphate 
maintains interactions with Arg627 and Lys631 in the a-helix of the fingers domain and with the metal ion and thus has the same conformation as in the catalytic NTP substrate complex. This suggests that the nucleotidyl transfer reaction does not require a conformational change in the polymerase and does not promote translocation prior to pyrophosphate release. Thus, it is likely that the dissociation of pyrophosphate leads to a conformational change in the fingers domain to "open" and allows translocation of the template-primer (Yin and Steitz 2004). This would support a power-stroke model of polymerase translocation over a Brownian-ratchet model because the energy from nucleotide incorporation, i.e., pyrophosphate release, drives a conformational change that "pushes" a polymerase forward on the template.

\subsection{Summary and Prospectus}

Viral polymerases have evolved to utilize replication strategies that are uniquely adapted to their hosts. They use a variety of mechanisms to initiate nucleic acid synthesis, prevent dissociation from nucleic acid during processive elongation, and coordinate multiple enzymatic activities. Compared to multisubunit cellular polymerases, many single-unit viral polymerases have all synthesizing activities and other functions necessary for genome replication. Unlike cellular host polymerases that require a strict regulation of transcription and replication, viral polymerases generally lack proofreading abilities and thus explore large areas of mutational space that could facilitate viral evolution. Although detailed knowledge of replication pathways, involvement of viral and cellular proteins in genome synthesis, and structural and functional characterization of viral polymerases is still limited to a few virus families, some common features of viral polymerases can be derived.

Viral RNA-dependent RNA polymerases and DNA-dependent DNA polymerases use several different mechanisms to ensure the initiation at the template terminus. The polymerase active site can generally accommodate five to seven nucleotides of template and primer strands; thus, it may not provide the interactions necessary to precisely position a template terminus and an NTP. Viruses overcome this problem by reducing the effective size of the template-binding channel using either a separate protein or a domain within a polymerase protein. The picornaviruses and the dsDNA phage $\varphi 29$ utilize a terminal protein that occupies most of the template-binding channel and mimics the primer terminus in the active site. Alternatively, flavivirus polymerases use a motif within the polymerase to occlude the active site so that only the template terminus can bind in the active site for initiation. In both cases, a terminal protein or the polymerase motif would need to move out of the template-binding channel after several cycles of nucleotide additions to accommodate the template and the growing chain.

The hallmark of the elongation phase is its high processivity. Although the rate and processivity have not been measured for many vial polymerases, it is likely that they synthesize the entire genome in one or a few trials. High processivity not only requires a tight polymerase-nucleic acid interaction to prevent dissociation, but should also allow relative movements between the polymerase and template at each step of polymerization. DNA-dependent DNA and RNA polymerases, which exhibit high processivity without any 
accessory proteins, encircle a template and growing chain within the polymerase and thus prevent dissociation from the polymerase. RNA-dependent RNA or DNA polymerases with wide open template-binding channels do not seem to have such motifs. In picornaviruses, the processivity of the polymerase increases in the presence of an accessory protein $3 \mathrm{AB}$. Thus, additional proteins in a replication complex may provide a similar function for RNAdependent polymerases.

Since the first structure of the Klenow fragment of DNA polymerase was solved, we have learned a great detail about the universal aspects of nucleic acid polymerase reactions. In particular, the two-metal mechanism used to stabilize the transition state of the nucleotidyl transfer step is common to all nucleic acid-synthesizing polymerases. Furthermore, selection of the correct NTP and catalysis are linked to a conformational change in the fingers domain that orients the incoming NTP in the catalytic site. A remaining fundamental question regarding the catalytic mechanism is how the chemical steps are linked to actual translocation of the template and daughter strands. Another active area of research is to understand how viral polymerases coordinate their nucleotide synthesizing activity with other enzymatic activities in the overall scheme of genome synthesis. For example, proofreading activities in DNA polymerases, $5^{\prime}$-capping of mRNA in RNA-dependent RNA polymerases, RNase $\mathrm{H}$ cleavage in reverse transcriptase, and protein-priming in hepatitis B virus reverse transcriptase are carried out by separate domains within a single polymerase protein, and hence, the mechanism of coordination of these additional catalytic activities with the basic polymerase reaction provides another layer of complexity that will need to be addressed.

\section{Acknowledgments}

I would like to thank Drs. Michael Rossmann, James Groarke, Marc Morais, Lucia Rothman-Denes, Peter Mason, and many colleagues who shared their passion for viruses with me throughout the years. The work is supported by NIH grants AI057156 and AI087856.

\section{References}

Abbondanzieri EA, Greenleaf WJ, Shaevitz JW, Landick R, Block SM. Direct observation of base-pair stepping by RNA polymerase. Nature. 2005; 438:460-465. [PubMed: 16284617]

Abbondanzieri EA, Bokinsky G, Rausch JW, Zhang JX, Le Grice SF, Zhuang X. Dynamic binding orientations direct activity of HIV reverse transcriptase. Nature. 2008; 453:184-189. [PubMed: 18464735]

Ackermann M, Padmanabhan R. De novo synthesis of RNA by the dengue virus RNA-dependent RNA polymerase exhibits temperature dependence at the initiation but not elongation phase. J Biol Chem. 2001; 276:39926-39937. [PubMed: 11546770]

Ago H, Adachi T, Yoshida A, Yamamoto M, Habuka N, Yatsunami K, Miyano M. Crystal structure of the RNA-dependent RNA polymerase of hepatitis C virus. Structure. 1999; 7:1417-1426. [PubMed: 10574802]

Baltimore D. Expression of animal virus genomes. Bacteriol Rev. 1971; 35:235-241. [PubMed: 4329869]

Basu VP, Song M, Gao L, Rigby ST, Hanson MN, Bambara RA. Strand transfer events during HIV-1 reverse transcription. Virus Res. 2008; 134:19-38. [PubMed: 18279992]

Berman AJ, Kamtekar S, Goodman JL, Lazaro JM, de Vega M, Blanco L, Salas M, Steitz TA. Structures of phi29 DNA polymerase complexed with substrate: the mechanism of translocation in B-family polymerases. EMBO J. 2007; 26:3494-3505. [PubMed: 17611604] 
Bishop DH, Gay ME, Matsuoko Y. Nonviral heterogeneous sequences are present at the 5' ends of one species of snowshoe hare bunyavirus S complementary RNA. Nucleic Acids Res. 1983; 11:6409_ 6418. [PubMed: 6312422]

Blanco L, Salas M. Relating structure to function in phi29 DNA polymerase. J Biol Chem. 1996; 271:8509-8512. [PubMed: 8621470]

Boivin S, Cusack S, Ruigrok RW, Hart DJ. Influenza A virus polymerase: structural insights into replication and host adaptation mechanisms. J Biol Chem. 2010; 285(37):28411-28417. [PubMed: 20538599]

Bressanelli S, Tomei L, Roussel A, Incitti I, Vitale RL, Mathieu M, De Francesco R, Rey FA. Crystal structure of the RNA-dependent RNA polymerase of hepatitis C virus. Proc Natl Acad Sci USA. 1999; 96:13034-13039. [PubMed: 10557268]

Broyles SS. Vaccinia virus transcription. J Gen Virol. 2003; 84:2293-2303. [PubMed: 12917449]

Cheetham GM, Steitz TA. Structure of a transcribing T7 RNA polymerase initiation complex. Science. 1999; 286:2305-2309. [PubMed: 10600732]

Choi KH, Groarke JM, Young DC, Kuhn RJ, Smith JL, Pevear DC, Rossmann MG. The structure of the RNA-dependent RNA polymerase from bovine viral diarrhea virus establishes the role of GTP in de novo initiation. Proc Natl Acad Sci USA. 2004; 101:4425-4430. [PubMed: 15070734]

Choi KH, Gallei A, Becher P, Rossmann MG. The structure of bovine viral diarrhea virus RNAdependent RNA polymerase and its amino-terminal domain. Structure. 2006; 14:1107-1113. [PubMed: 16843892]

Choi KH, Rossmann MG. RNA-dependent RNA polymerases from Flaviviridae. Curr Opin Struct Biol. 2009; 19(6):746-751. [PubMed: 19914821]

Delarue M, Poch O, Tordo N, Moras D, Argos P. An attempt to unify the structure of polymerases. Protein Eng. 1990; 3:461-467. [PubMed: 2196557]

DeStefano JJ, Mallaber LM, Fay PJ, Bambara RA. Quantitative analysis of RNA cleavage during RNA-directed DNA synthesis by human immunodeficiency and avian myeloblastosis virus reverse transcriptases. Nucleic Acids Res. 1994; 22:3793-3800. [PubMed: 7524028]

Drake JW. A constant rate of spontaneous mutation in DNA-based microbes. Proc Natl Acad Sci USA. 1991; 88:7160-7164. [PubMed: 1831267]

Dufour E, Rodriguez I, Lazaro JM, de Vega M, Salas M. A conserved insertion in protein-primed DNA polymerases is involved in primer terminus stabilisation. J Mol Biol. 2003; 331:781-794. [PubMed: 12909010]

Durniak KJ, Bailey S, Steitz TA. The structure of a transcribing T7 RNA polymerase in transition from initiation to elongation. Science. 2008; 322:553-557. [PubMed: 18948533]

Egloff MP, Decroly E, Malet H, Selisko B, Benarroch D, Ferron F, Canard B. Structural and functional analysis of methylation and 5'-RNA sequence requirements of short capped RNAs by the methyltransferase domain of dengue virus NS5. J Mol Biol. 2007; 372:723-736. [PubMed: 17686489]

Ferrer-Orta C, Arias A, Perez-Luque R, Escarmis C, Domingo E, Verdaguer N. Structure of foot-andmouth disease virus RNA-dependent RNA polymerase and its complex with a template-primer RNA. J Biol Chem. 2004; 279:47212-47221. [PubMed: 15294895]

Ferrer-Orta C, Arias A, Agudo R, Perez-Luque R, Escarmis C, Domingo E, Verdaguer N. The structure of a protein primer-polymerase complex in the initiation of genome replication. EMBO J. 2006; 25:880-888. [PubMed: 16456546]

Ferrer-Orta C, Arias A, Perez-Luque R, Escarmis C, Domingo E, Verdaguer N. Sequential structures provide insights into the fidelity of RNA replication. Proc Natl Acad Sci USA. 2007; 104:94639468. [PubMed: 17517631]

Furfine ES, Reardon JE. Reverse transcriptase.RNase H from the human immunodeficiency virus. Relationship of the DNA polymerase and RNA hydrolysis activities. J Biol Chem. 1991; 266:406412. [PubMed: 1702425]

Gao G, Orlova M, Georgiadis MM, Hendrickson WA, Goff SP. Conferring RNA polymerase activity to a DNA polymerase: a single residue in reverse transcriptase controls substrate selection. Proc Natl Acad Sci USA. 1997; 94:407-411. [PubMed: 9012795] 
Golomb M, Chamberlin M. Characterization of T7-specific ribonucleic acid polymerase. IV. Resolution of the major in vitro transcripts by gel electrophoresis. J Biol Chem. 1974; 249(9): 2858-2863. [PubMed: 4828324]

$\mathrm{Gu}$ M, Lima CD. Processing the message: structural insights into capping and decapping mRNA. Curr Opin Struct Biol. 2005; 15:99-106. [PubMed: 15718140]

Guajardo R, Sousa R. A model for the mechanism of polymerase translocation. J Mol Biol. 1997; 265:8-19. [PubMed: 8995520]

Hansen JL, Long AM, Schultz SC. Structure of the RNA-dependent RNA polymerase of poliovirus. Structure. 1997; 5:1109-1122. [PubMed: 9309225]

Hogg M, Wallace SS, Doublie S. Crystallographic snapshots of a replicative DNA polymerase encountering an abasic site. EMBO J. 2004; 23:1483-1493. [PubMed: 15057283]

Hong Z, Cameron CE, Walker MP, Castro C, Yao N, Lau JY, Zhong W. A novel mechanism to ensure terminal initiation by hepatitis C virus NS5B polymerase. Virology. 2001; 285:6-11. [PubMed: 11414800]

Huang H, Chopra R, Verdine GL, Harrison SC. Structure of a covalently trapped catalytic complex of HIV-1 reverse transcriptase: implications for drug resistance. Science. 1998; 282:1669-1675. [PubMed: 9831551]

Ibarra B, Chemla YR, Plyasunov S, Smith SB, Lazaro JM, Salas M, Bustamante C. Proofreading dynamics of a processive DNA polymerase. EMBO J. 2009; 28:2794-2802. [PubMed: 19661923]

Jacobo-Molina A, Ding J, Nanni RG, Clark AD Jr, Lu X, Tantillo C, Williams RL, Kamer G, Ferris $\mathrm{AL}$, Clark $\mathrm{P}$, et al. Crystal structure of human immunodeficiency virus type 1 reverse transcriptase complexed with double-stranded DNA at 3.0 A resolution shows bent DNA. Proc Natl Acad Sci USA. 1993; 90:6320-6324. [PubMed: 7687065]

Jeruzalmi D, Steitz TA. Structure of T7 RNA polymerase complexed to the transcriptional inhibitor T7 lysozyme. EMBO J. 1998; 17:4101-4113. [PubMed: 9670025]

Julias JG, McWilliams MJ, Sarafianos SG, Arnold E, Hughes SH. Mutations in the RNase H domain of HIV-1 reverse transcriptase affect the initiation of DNA synthesis and the specificity of RNase H cleavage in vivo. Proc Natl Acad Sci USA. 2002; 99:9515-9520. [PubMed: 12093908]

Kamtekar S, Berman AJ, Wang J, Lazaro JM, de Vega M, Blanco L, Salas M, Steitz TA. The phi29 DNA polymerase:protein-primer structure suggests a model for the initiation to elongation transition. EMBO J. 2006; 25:1335-1343. [PubMed: 16511564]

Kao CC, Del Vecchio AM, Zhong W. De novo initiation of RNA synthesis by a recombinant flaviviridae RNA-dependent RNA polymerase. Virology. 1999; 253:1-7. [PubMed: 9887312]

Kasamatsu H, Nakanishi A. How do animal DNA viruses get to the nucleus? Annu Rev Microbiol. 1998; 52:627-686. [PubMed: 9891810]

Kim S, Lee J, Ryu WS. Four conserved cysteine residues of the hepatitis B virus polymerase are critical for RNA pregenome encapsidation. J Virol. 2009; 83:8032-8040. [PubMed: 19515776]

Kohlstaedt LA, Steitz TA. Reverse transcriptase of human immunodeficiency virus can use either human tRNA(3Lys) or Escherichia coli tRNA(2Gln) as a primer in an in vitro primer-utilization assay. Proc Natl Acad Sci USA. 1992; 89:9652-9656. [PubMed: 1384059]

Kohlstaedt LA, Wang J, Friedman JM, Rice PA, Steitz TA. Crystal structure at 3.5 A resolution of HIV-1 reverse transcriptase complexed with an inhibitor. Science. 1992; 256:1783-1790. [PubMed: 1377403]

Krug MS, Berger SL. Ribonuclease H activities associated with viral reverse transcriptases are endonucleases. Proc Natl Acad Sci USA. 1989; 86:3539-3543. [PubMed: 2471188]

Lai VC, Kao CC, Ferrari E, Park J, Uss AS, Wright-Minogue J, Hong Z, Lau JY. Mutational analysis of bovine viral diarrhea virus RNA-dependent RNA polymerase. J Virol. 1999; 73:10129-10136. [PubMed: 10559328]

Lazaro JM, Blanco L, Salas M. Purification of bacteriophage phi 29 DNA polymerase. Methods Enzymol. 1995; 262:42-49. [PubMed: 8594366]

Lelke M, Brunotte L, Busch C, Gunther S. An N-terminal region of Lassa virus L protein plays a critical role in transcription but not replication of the virus genome. J Virol. 2010; 84:1934-1944. [PubMed: 20007273] 
Lesburg CA, Cable MB, Ferrari E, Hong Z, Mannarino AF, Weber PC. Crystal structure of the RNAdependent RNA polymerase from hepatitis $C$ virus reveals a fully encircled active site. Nat Struct Biol. 1999; 6:937-943. [PubMed: 10504728]

Luo G, Hamatake RK, Mathis DM, Racela J, Rigat KL, Lemm J, Colonno RJ. De novo initiation of RNA synthesis by the RNA-dependent RNA polymerase (NS5B) of hepatitis C virus. J Virol. 2000; 74:851-863. [PubMed: 10623748]

Malet H, Egloff MP, Selisko B, Butcher RE, Wright PJ, Roberts M, Gruez A, Sulzenbacher G, Vonrhein C, Bricogne G, Mackenzie JM, Khromykh AA, Davidson AD, Canard B. Crystal structure of the RNA polymerase domain of the West Nile virus non-structural protein 5. J Biol Chem. 2007; 282:10678-10689. [PubMed: 17287213]

Masters BS, Stohl LL, Clayton DA. Yeast mitochondrial RNA polymerase is homologous to those encoded by bacteriophages T3 and T7. Cell. 1987; 51:89-99. [PubMed: 3308116]

Meijer WJ, Horcajadas JA, Salas M. Phi29 family of phages. Microbiol Mol Biol Rev. 2001; 65:261287. second page, table of contents. [PubMed: 11381102]

Mendez J, Blanco L, Salas M. Protein-primed DNA replication: a transition between two modes of priming by a unique DNA polymerase. EMBO J. 1997; 16:2519-2527. [PubMed: 9171364]

Mesters JR, Tan J, Hilgenfeld R. Viral enzymes. Curr Opin Struct Biol. 2006; 16:776-786. [PubMed: 17085042]

Morin B, Coutard B, Lelke M, Ferron F, Kerber R, Jamal S, Frangeul A, Baronti C, Charrel R, de Lamballerie X, Vonrhein C, Lescar J, Bricogne G, Gunther S, Canard B. The N-terminal domain of the arenavirus $\mathrm{L}$ protein is an RNA endonuclease essential in mRNA transcription. PLoS Pathog. 2010; 6:e1001038. [PubMed: 20862324]

Murray KE, Barton DJ. Poliovirus CRE-dependent VPg uridylylation is required for positive-strand RNA synthesis but not for negative-strand RNA synthesis. J Virol. 2003; 77:4739-4750. [PubMed: 12663781]

Nassal M. Hepatitis B viruses: reverse transcription a different way. Virus Res. 2008; 134:235-249. [PubMed: 18339439]

Ng KK, Cherney MM, Vazquez AL, Machin A, Alonso JM, Parra F, James MN. Crystal structures of active and inactive conformations of a caliciviral RNA-dependent RNA polymerase. J Biol Chem. 2002; 277:1381-1387. [PubMed: 11677245]

Ollis DL, Brick P, Hamlin R, Xuong NG, Steitz TA. Structure of large fragment of Escherichia coli DNA polymerase I complexed with dTMP. Nature. 1985; 313:762-766. [PubMed: 3883192]

Orlowski J, Bujnicki JM. Structural and evolutionary classification of Type II restriction enzymes based on theoretical and experimental analyses. Nucleic Acids Res. 2008; 36:3552-3569. [PubMed: 18456708]

Paul AV, Peters J, Mugavero J, Yin J, van Boom JH, Wimmer E. Biochemical and genetic studies of the VPg uridylylation reaction catalyzed by the RNA polymerase of poliovirus. J Virol. 2003a; 77:891-904. [PubMed: 12502805]

Paul AV, Yin J, Mugavero J, Rieder E, Liu Y, Wimmer E. A “slide-back” mechanism for the initiation of protein-primed RNA synthesis by the RNA polymerase of poliovirus. J Biol Chem. 2003b; 278:43951-43960. [PubMed: 12937178]

Plotch SJ, Bouloy M, Ulmanen I, Krug RM. A unique cap(m7G pppXm)-dependent influenza virion endonuclease cleaves capped RNAs to generate the primers that initiate viral RNA transcription. Cell. 1981; 23:847-858. [PubMed: 6261960]

Poch O, Sauvaget I, Delarue M, Tordo N. Identification of four conserved motifs among the RNAdependent polymerase encoding elements. EMBO J. 1989; 8:3867-3874. [PubMed: 2555175]

Polyak SJ, Zheng S, Harnish DG. 5' termini of Pichinde arenavirus S RNAs and mRNAs contain nontemplated nucleotides. J Virol. 1995; 69:3211-3215. [PubMed: 7707553]

Radziwill G, Tucker W, Schaller H. Mutational analysis of the hepatitis B virus P gene product: domain structure and RNase H activity. J Virol. 1990; 64:613-620. [PubMed: 2153228]

Ranjith-Kumar CT, Kim YC, Gutshall L, Silverman C, Khandekar S, Sarisky RT, Kao CC. Mechanism of de novo initiation by the hepatitis $\mathrm{C}$ virus RNA-dependent RNA polymerase: role of divalent metals. J Virol. 2002; 76:12513-12525. [PubMed: 12438577] 
Rausch JW, Lener D, Miller JT, Julias JG, Hughes SH, Le Grice SF. Altering the RNase H primer grip of human immunodeficiency virus reverse transcriptase modifies cleavage specificity. Biochemistry. 2002; 41:4856-4865. [PubMed: 11939780]

Reguera J, Weber F, Cusack S. Bunyaviridae RNA polymerases (L-protein) have an N-terminal, influenza-like endonuclease domain, essential for viral cap-dependent transcription. PLoS Pathog. 2010; 6:e1001101. [PubMed: 20862319]

Rodgers DW, Gamblin SJ, Harris BA, Ray S, Culp JS, Hellmig B, Woolf DJ, Debouck C, Harrison SC. The structure of unliganded reverse transcriptase from the human immunodeficiency virus type 1. Proc Natl Acad Sci USA. 1995; 92:1222-1226. [PubMed: 7532306]

Rodriguez I, Lazaro JM, Blanco L, Kamtekar S, Berman AJ, Wang J, Steitz TA, Salas M, de Vega M. A specific subdomain in phi29 DNA polymerase confers both processivity and stranddisplacement capacity. Proc Natl Acad Sci USA. 2005; 102:6407-6412. [PubMed: 15845765]

Rodriguez-Wells V, Plotch SJ, DeStefano JJ. Primer-dependent synthesis by poliovirus RNAdependent RNA polymerase (3D(pol)). Nucleic Acids Res. 2001; 29:2715-2724. [PubMed: 11433016]

Rothwell PJ, Waksman G. Structure and mechanism of DNA polymerases. Adv Protein Chem. 2005; 71:401-440. [PubMed: 16230118]

Sarafianos SG, Das K, Tantillo C, Clark AD Jr, Ding J, Whitcomb JM, Boyer PL, Hughes SH, Arnold E. Crystal structure of HIV-1 reverse transcriptase in complex with a polypurine tract RNA:DNA. EMBO J. 2001; 20:1449-1461. [PubMed: 11250910]

Sarafianos SG, Marchand B, Das K, Himmel DM, Parniak MA, Hughes SH, Arnold E. Structure and function of HIV-1 reverse transcriptase: molecular mechanisms of polymerization and inhibition. J Mol Biol. 2009; 385:693-713. [PubMed: 19022262]

Sohn JA, Litwin S, Seeger C. Mechanism for CCC DNA synthesis in hepadnaviruses. PLoS One. 2009; 4:e8093. [PubMed: 19956651]

Sousa R, Chung YJ, Rose JP, Wang BC. Crystal structure of bacteriophage T7 RNA polymerase at 3.3 A resolution. Nature. 1993; 364:593-599. [PubMed: 7688864]

Steitz TA. A mechanism for all polymerases. Nature. 1998; 391:231-232. [PubMed: 9440683]

Tahirov TH, Temiakov D, Anikin M, Patlan V, McAllister WT, Vassylyev DG, Yokoyama S. Structure of a T7 RNA polymerase elongation complex at 2.9 A resolution. Nature. $2002 ; 420$ :4350. [PubMed: 12422209]

Temiakov D, Mentesana PE, Ma K, Mustaev A, Borukhov S, McAllister WT. The specificity loop of T7 RNA polymerase interacts first with the promoter and then with the elongating transcript, suggesting a mechanism for promoter clearance. Proc Natl Acad Sci USA. 2000; 97:14109-14114. [PubMed: 11095736]

Thompson AA, Peersen OB. Structural basis for proteolysis-dependent activation of the poliovirus RNA-dependent RNA polymerase. EMBO J. 2004; 23:3462-3471. [PubMed: 15306852]

Truniger V, Lazaro JM, Salas M, Blanco L. A DNA binding motif coordinating synthesis and degradation in proofreading DNA polymerases. EMBO J. 1996; 15:3430-3441. [PubMed: 8670845]

Truniger V, Blanco L, Salas M. Role of the "YxGG/A" motif of Phi29 DNA polymerase in proteinprimed replication. J Mol Biol. 1999; 286:57-69. [PubMed: 9931249]

Uchil PD, Satchidanandam V. Architecture of the flaviviral replication complex. Protease, nuclease, and detergents reveal encasement within double-layered membrane compartments. J Biol Chem. 2003; 278:24388-24398. [PubMed: 12700232]

van Dijk AA, Makeyev EV, Bamford DH. Initiation of viral RNA-dependent RNA polymerization. J Gen Virol. 2004; 85:1077-1093. [PubMed: 15105525]

Wang HY, Elston T, Mogilner A, Oster G. Force generation in RNA polymerase. Biophys J. 1998; 74:1186-1202. [PubMed: 9512018]

Weigel C, Seitz H. Bacteriophage replication modules. FEMS Microbiol Rev. 2006; 30:321-381. [PubMed: 16594962]

Wendeler, M.; Miller, JT.; Le Grice, SFJ. Human immunodeficiency virus reverse transcriptase.. In: Cameron, Craig E.; Gotte, Matthias; Raney, Kevin D., editors. Viral genome replication. Springer Science + Business Media; New York: 2009. p. 403-427. 
Yap TL, Xu T, Chen YL, Malet H, Egloff MP, Canard B, Vasudevan SG, Lescar J. Crystal structure of the dengue virus RNA-dependent RNA polymerase catalytic domain at 1.85-angstrom resolution. J Virol. 2007; 81:4753-4765. [PubMed: 17301146]

Yin YW, Steitz TA. Structural basis for the transition from initiation to elongation transcription in T7 RNA polymerase. Science. 2002; 298:1387-1395. [PubMed: 12242451]

Yin YW, Steitz TA. The structural mechanism of translocation and helicase activity in T7 RNA polymerase. Cell. 2004; 116:393-404. [PubMed: 15016374]

Zamyatkin DF, Parra F, Alonso JM, Harki DA, Peterson BR, Grochulski P, Ng KK. Structural insights into mechanisms of catalysis and inhibition in Norwalk virus polymerase. J Biol Chem. 2008; 283:7705-7712. [PubMed: 18184655] 


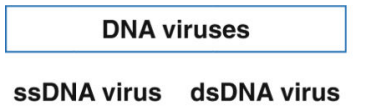

$$
\text { ssDNA }
$$

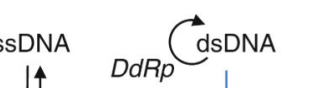
$D d R p$

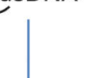

Dap $D d R p$

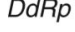

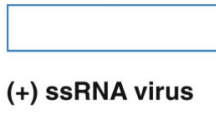

RNA viruses

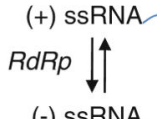

(-) SSRNA
(-) ssRNA virus

dsRNA virus

$$
\begin{aligned}
& \text { (-) ssRNA } \\
& R d R p \mid \uparrow
\end{aligned}
$$

(+) ssRNA

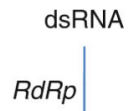

Reverse transcribing viruses

ssRNA-rt virus dsDNA-rt virus

(+) ssRNA

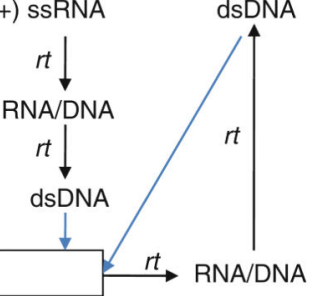

Fig. 12.1.

Baltimore virus classification scheme based on genome type and method of mRNA synthesis (Baltimore 1971). The seven virus classes are DNA (ssDNA and dsDNA), RNA (plus-sense (+) ssRNA, minus-sense (-) ssRNA, and dsRNA), and reverse-transcribing (ssRNA-reverse transcribing (rt) and dsDNA-rt) viruses. Viral genome transcription and replication steps are shown as blue and black arrows, respectively. The steps that viral polymerases catalyze are indicated with RNA-dependent RNA polymerase (RdRp), reverse transcriptase (rt), DNA-dependent DNA polymerase (DdDp), and DNA-dependent RNA polymerase (DdRp). Viral plus-sense RNA can serve as an mRNA and does not require modification for transcription. Note that many eukaryotic dsDNA viruses do not encode a viral polymerase and instead use cellular enzymes in the nucleus for viral genome transcription and replication 


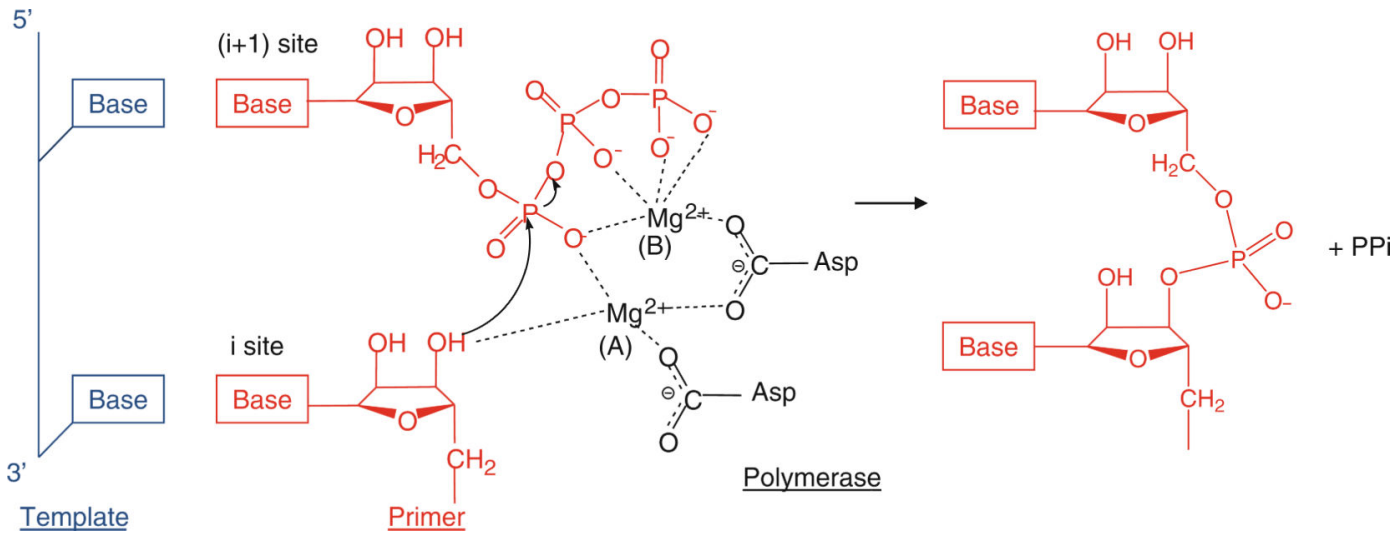

Fig. 12.2.

Two-metal mechanism used by polymerases to catalyze the nucleotidyl transfer reaction. Template, primer, and polymerase residues are shown in blue, red, and black, respectively. The polymerase active site contains the binding sites for a template, the RNA or DNA terminus (the initiation, "i", or priming site), and the incoming NTP (the " $i+1$ " site). Two metal ions, $\mathrm{A}$ and $\mathrm{B}$, are coordinated by the conserved Asp residues in the polymerase active site. Metal ion A binds to the $3^{\prime}-\mathrm{OH}$ of the primer terminus and lowers the affinity of the $3^{\prime}-$ $\mathrm{OH}$ for its hydrogen, facilitating a nucleophilic attack of $3^{\prime}-\mathrm{O}^{-}$on the a-phosphate of the incoming NTP (Steitz 1998). Metal ion B stabilizes the incoming NTP and pyrophosphate (ppi) leaving group 
a

$$
\begin{aligned}
& \text { RdRp Polio } 230 \quad \frac{A}{\text { AFDYTG.Y }} \quad 46 \frac{B}{\text { GMPSGCSGT.SI }} \quad 25 \frac{C}{\text { YGDDV }} 20 \frac{D}{\text { TPADKSA }} \\
& \text { WN } 534 \text { ADDTAG.W } 59 \text { QRGSGQVVT.YA } 54 \text { SGDDC } 16 \text { NAMSEKVR } \\
& \begin{array}{lllllllll}
\text { Influ } & 304 & \text { TGDLKKYCL } & 91 & \text { SLSPGMMMG..N } & 31 & \text { SSDDF } & 27 & \text {.SKKKKSY }
\end{array} \\
& \text { LCMV } 1169 \text { SMDHSK.WG } 93 \text { DMGQGILHN..A } 25 \text { SSDDQ } 44 \text {.EAFK彑SR }
\end{aligned}
$$

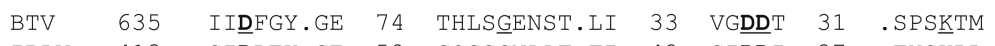

$$
\begin{aligned}
& \text { IBDV } 413 \text { SIDLEK.GE } 58 \text { GQGSGNAAT.FI } 42 \text { SIDDI } 37 \text {.TYSKELL }
\end{aligned}
$$

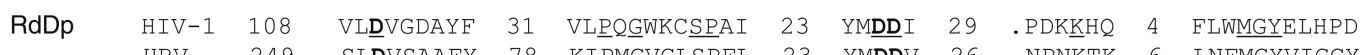

$$
\begin{aligned}
& \text { DdRp } \quad \text { T7 } 536 \quad \frac{\mathrm{A}}{\text { AFDGSCSGI }} 103 \frac{\mathrm{B}}{\underline{\underline{K R S V M T L A Y G}}} \quad 187 \frac{\mathrm{C}}{\text { ALIHDS }}
\end{aligned}
$$

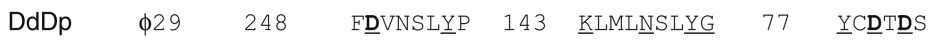

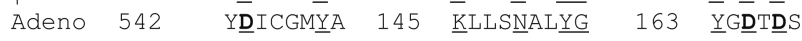

b

Fig. 12.3.

Polymerase sequence motifs in RNA-dependent and DNA-dependent polymerases. (a) Alignment of the RNA-dependent polymerase motifs A, B, C, D, and E. The alignment includes RdRps encoded by plus-sense ssRNA viruses (poliovirus and West Nile virus), minus-sense ssRNA viruses (influenza and Lassa viruses), dsRNA viruses (bluetongue and infectious bursal disease viruses), and DdRps (reverse transcriptases) encoded by a ssRNA virus (human immune deficiency virus type 1) and a dsDNA virus (hepatitis B virus). The numbers of residues separating the motifs are indicated. (b) Alignment of the DNAdependent polymerase motifs $\mathrm{A}, \mathrm{B}$, and $\mathrm{C}$. The alignment includes DdDps encoded by bacteriophages T7 and N4, and DdRps encoded by bacteriophages $\varphi 29$ and adenovirus. DNA-dependent polymerase motifs $\mathrm{A}$ and $\mathrm{C}$ and RNA-dependent polymerase motifs $\mathrm{A}$ and $\mathrm{C}$ coordinate divalent metal ions for catalytic activity 
a

Oligonucleotide

priming

Cap-snatching

Protein priming

b

De novo
5

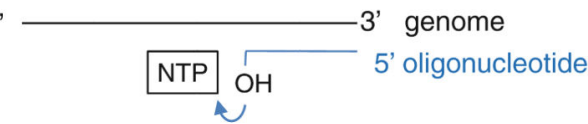

5

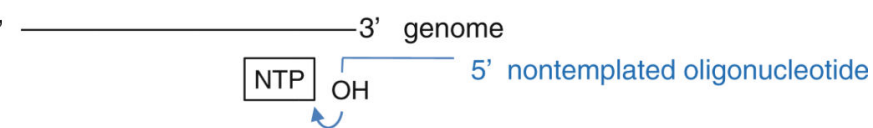

5

3' genome

NTP Ser, Tyr Terminal protein

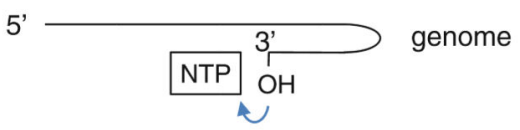

5

3' genome

NTP NTP

$\mathrm{OH}$

Fig. 12.4.

Schematic diagram of initiation mechanisms of viral polymerases. (a) Primer-dependent initiation. The primers can be an oligonucleotide, a snatched cap from host mRNA, a terminal protein, or the $3^{\prime}$-terminus of the template strand that folds back onto itself. (b) De novo initiation. The $3^{\prime}$-hydroxyl group of the initiation NTP attacks the a-phosphate of the incoming NTP 
a

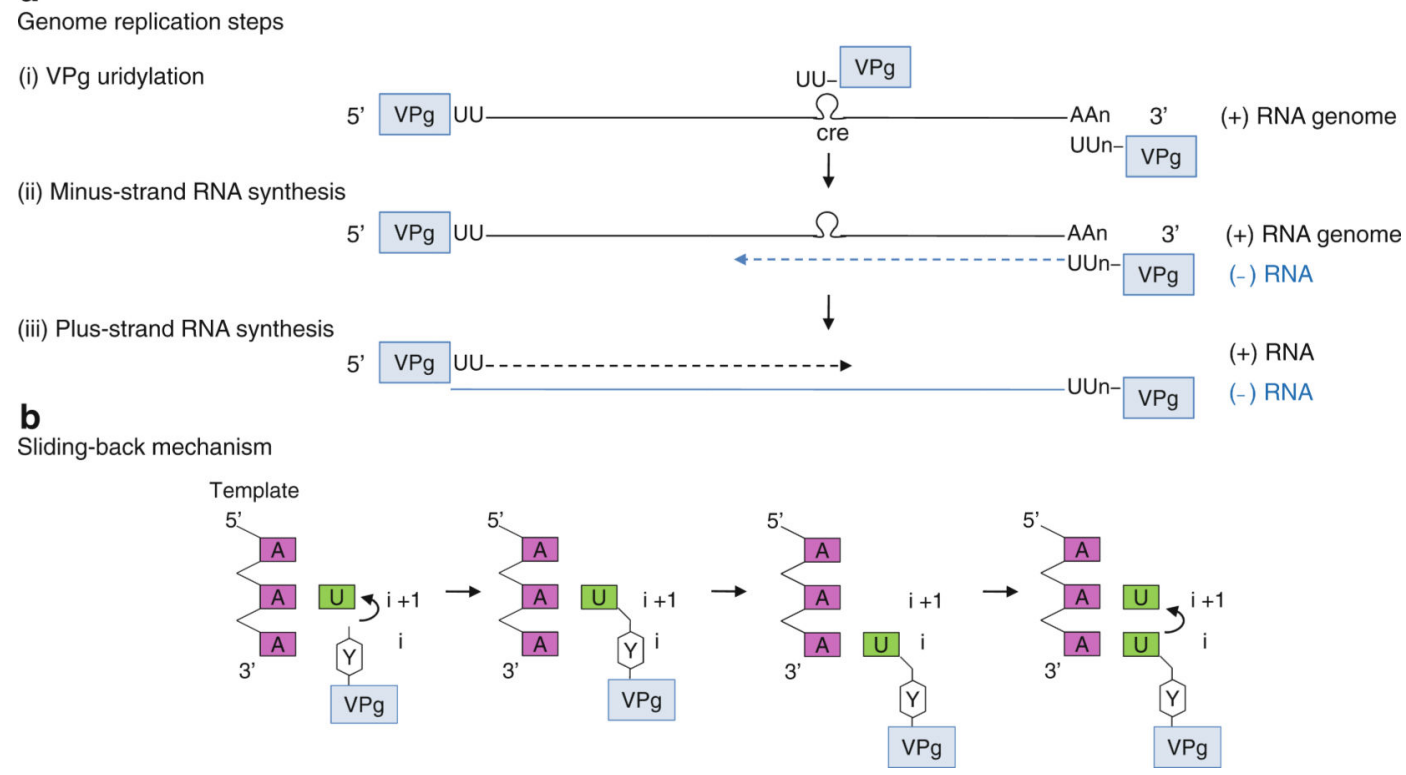

Fig. 12.5.

Poliovirus genome replication. (a) Genome replication steps. (i) VPg uridylation. Terminal protein VPg is covalently attached to the $5^{\prime}$-end of plus-sense viral genome. The hydroxyl group of VPg Tyr3 acts analogously to the free $3^{\prime}-\mathrm{OH}$ of the primer terminus to form an uridylated form of VPg, VPg-pU, which is then further elongated to VPg-pUpU. The VPgpUpU can be synthesized from either the poly(A) tail or conserved cis-acting replication element (CRE) as a template. (ii) Minus-strand RNA synthesis. VPg-pUpU is used as a primer to base-pair with a plus-strand genome and elongated to form a VPg-linked minusstrand RNA (blue strand). (iii) Plus-strand RNA synthesis. The VPg-pUpU made using the $\mathrm{CRE}$ as a template is used as a primer for plus-strand RNA synthesis in the subsequent step. Thus, both plus- and minus-strand RNAs are VPg-linked at their 5'-ends in vivo. (b) Schematic of the sliding-back mechanism. The polymerase initiates VPg uridylation at the second A on the $3^{\prime}$-end template. The VPg-pU then slides back one base to base-pair with the $3^{\prime}$-terminal A, and the polymerase begins second uridylation reaction. Thus, the slidingback mechanism requires two sequential adenosines in the template 

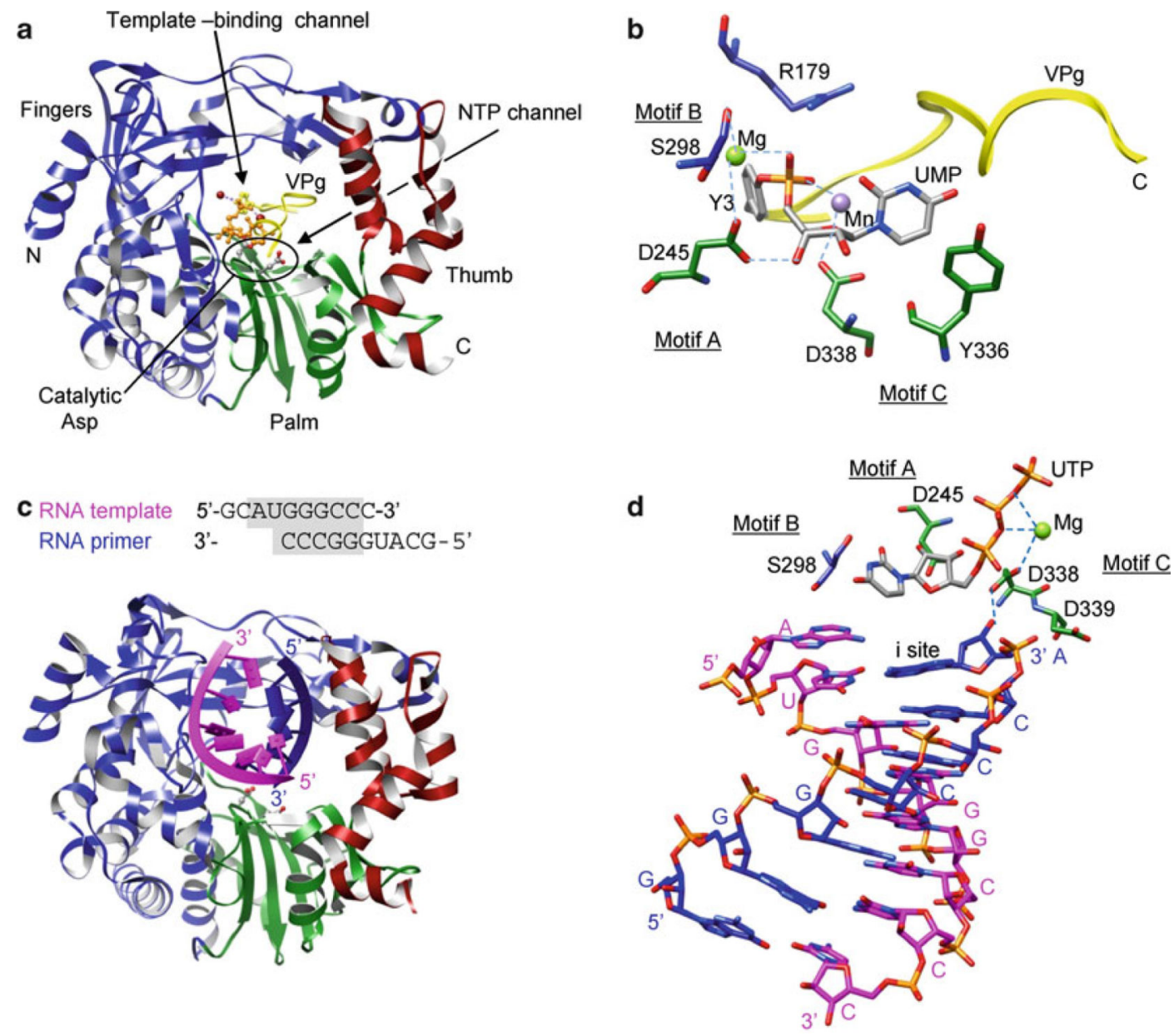

Fig. 12.6.

Crystal structures of 3D polymerase that use VPg-linked primers. (a) FMDV 3D polymerase and VPg-pU complex. The fingers, palm, and thumb domains are shown in blue, green, and $r e d$, respectively. The active site residues in the GDD motif are depicted as ball-and-stick models. The UMP moiety in VPg-pU is shown as an orange ball-and-stick model. (b) Active site in a VPg-pU complex. Tyr3 and the UMP moiety of VPg-pU are shown as gray sticks. The active site residues are colored according to their domains as in (A), and polymerase sequence motifs are labeled. (c) 3D polymerase and template-primer complex. The template and primer strands are shown in magenta and blue, respectively. (d) 3D polymerase and template-primer-NTP complex (open form). Note that the incoming NTP (UTP) does not base-pair with the template base at the " $i+1$ " site, although the triphosphate moiety interacts with a metal ion in the active site 


\section{a}

Minus-strand RNA synthesis

5

b

Plus-strand RNA synthesis

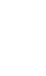

3' (+) RNA genome

(-) RNA

(+) RNA

(-) RNA

Fig. 12.7.

Flavivirus genome replication. (a) Minus-strand RNA synthesis. The viral RdRp uses a plussense viral genome as a template to synthesize minus-strand RNA without a primer (de novo). Minus-strand RNA forms a dsRNA with plus-sense RNA. (b) Plus-strand RNA synthesis. Plus-sense RNA is synthesized using a minus-strand RNA in a dsRNA intermediate as a template via de novo initiation. In flavivirus, the newly synthesized plusstrand RNA is capped at its $5^{\prime}$-end by the viral replication complex 

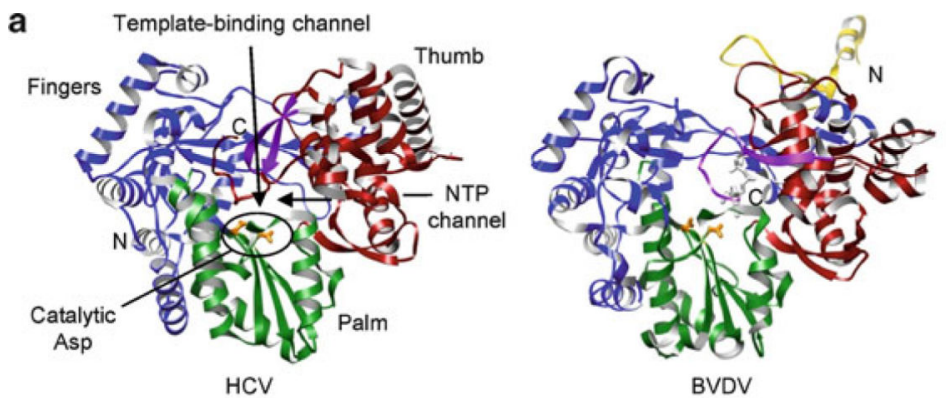

BVDV

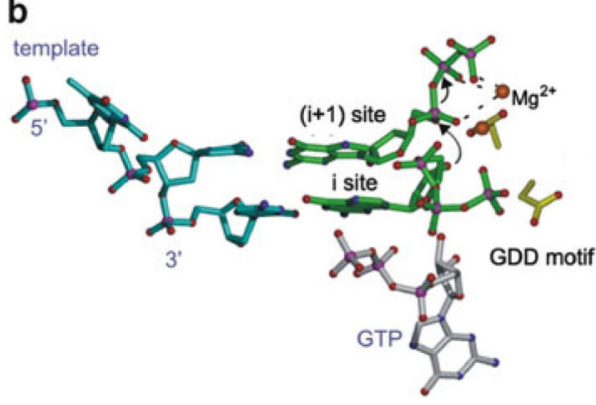

$\mathbf{C}_{\text {tom }}$

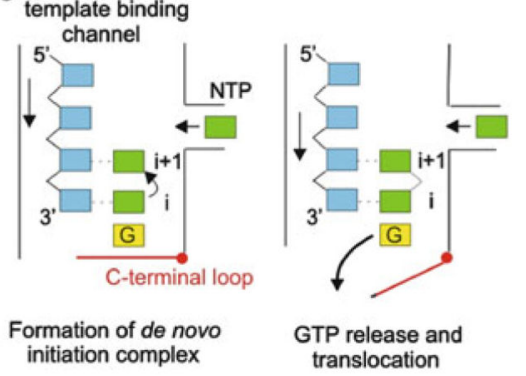

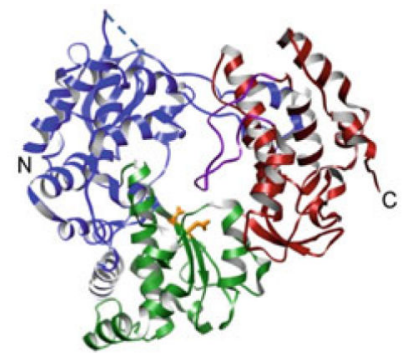

West Nile

Fig. 12.8.

The Flaviviridae RNA-dependent RNA polymerases that use a de novo initiation mechanism. (a) Hepatitis C virus (HCV), Bovine viral diarrhea virus (pestivirus, BVDV), and West Nile virus (flavivirus) are shown with their fingers, palm, and thumb domains colored in blue, green, and red, respectively. The yellow region of BVDV polymerase is a part of the $\mathrm{N}$-terminal domain. The $\mathrm{C}$-terminal motif in the thumb domain that occludes the active site is shown in purple, and active site residues are shown as orange sticks. (b) Model of initiation complex illustrating the proposed role of the de novo GTP. The role of GTP in de novo initiation may be to stabilize the initiating NTP at the " $\mathrm{i}$ " site. (c) Schematic of de novo initiation in Flaviviridae polymerases. The initiation complex, consisting of template (blue), two NTPs (green), and GTP (yellow), is assembled in the active site. The C-terminal loop is closed to further stabilize the initiation complex. After the nucleotidyl transfer reaction, the GTP molecule required for stabilizing the initiation NTP is released and the template-primer translocates by one base. The C-terminal loop in the thumb domain opens up to allow dsRNA to move out of the active site and the polymerase transitions from the initiation to the elongation phase (Choi and Rossmann 2009) 
Influenza virus polymerase

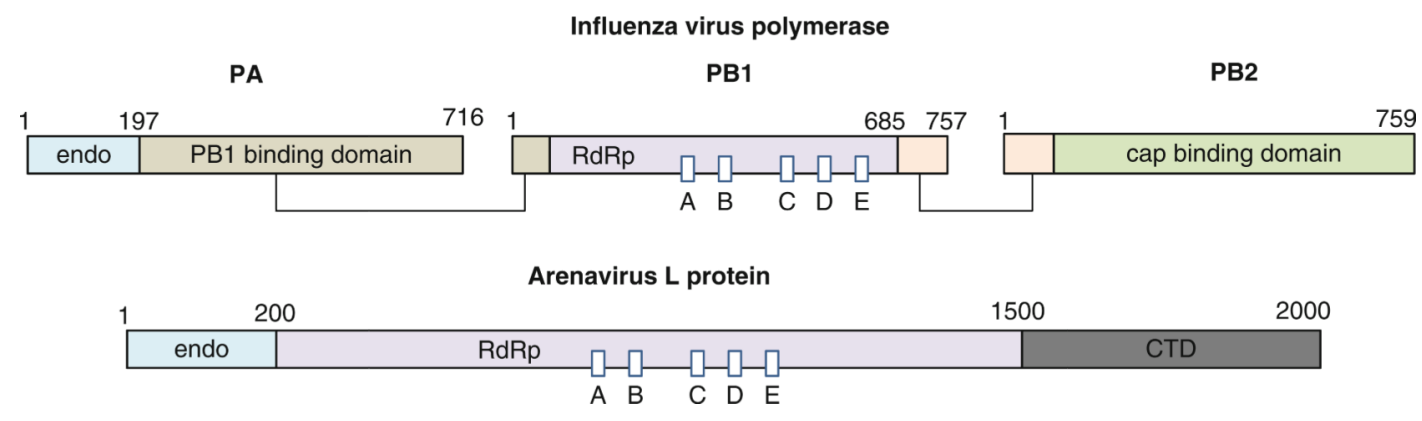

Fig. 12.9.

Domain arrangement of RNA-dependent RNA polymerases from negative-sense ssRNA viruses. Influenza virus polymerase consists of three subunits, PA, PB1, and PB2 (top). All RNA polymerase motifs are found in PB1. The N-terminal domain of PA has an endonuclease (endo) activity that is proposed to be involved in the cap-snatching mechanism. Domains known to interact with each other are shown in the same color and are connected with lines (Boivin et al. 2010). Arenavirus L protein consists of a single polypeptide chain of 2,000 amino acids (bottom). Endonuclease (endo), RNA-dependent RNA polymerase (RdRp), and C-terminal domains (CTD) are labeled. Sequence motifs common to all RdRps (boxed and labeled A-E) are shown with the active site Ser-Asp-Asp (GDD) motif located in box $\mathrm{C}$ 


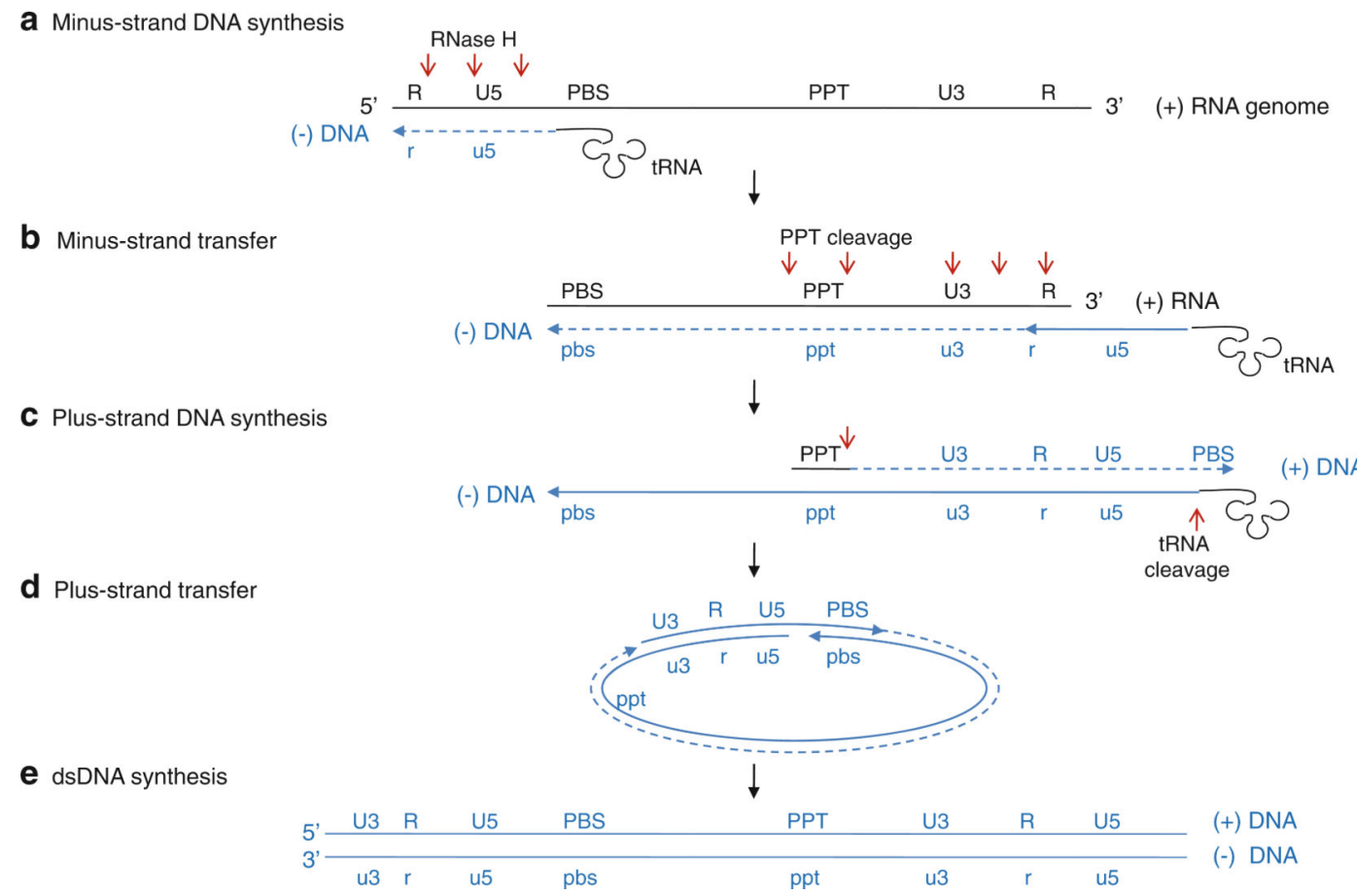

Fig. 12.10.

Reverse transcription of the HIV-1 genome. (a) Minus-strand DNA synthesis. Minus-sense DNA synthesis is initiated near the $5^{\prime}$-end of the RNA genome using a tRNA as a primer that anneals at the primer-binding site (PBS). During the DNA synthesis, RNase $\mathrm{H}$ cleaves RNA segments of RNA-DNA hybrid (red arrows). (b) Minus-strand transfer. The singlestranded minus-strand DNA anneals with the repeat R region at the 3 '-end of RNA genome and continues to elongate. (c) Plus-strand DNA synthesis. The polypurine track (PPT), which is resistant to RNase $\mathrm{H}$, is used as a primer to initiate plus-sense DNA synthesis. The synthesis stops after copying the PBS region from tRNA, and RNase H cleaves tRNA. (d) Plus-strand transfer. The plus-strand DNA is transferred and annealed with the PBS region of the minus-strand DNA, and DNA synthesis continues via bidirectional DNA synthesis. (e) dsDNA synthesis. Ligation of a circular intermediate produces a linear dsDNA with terminal repeats containing $\mathrm{R}$ and promoter regions (U3 and U5) at both ends (Wendeler et al. 2009) 

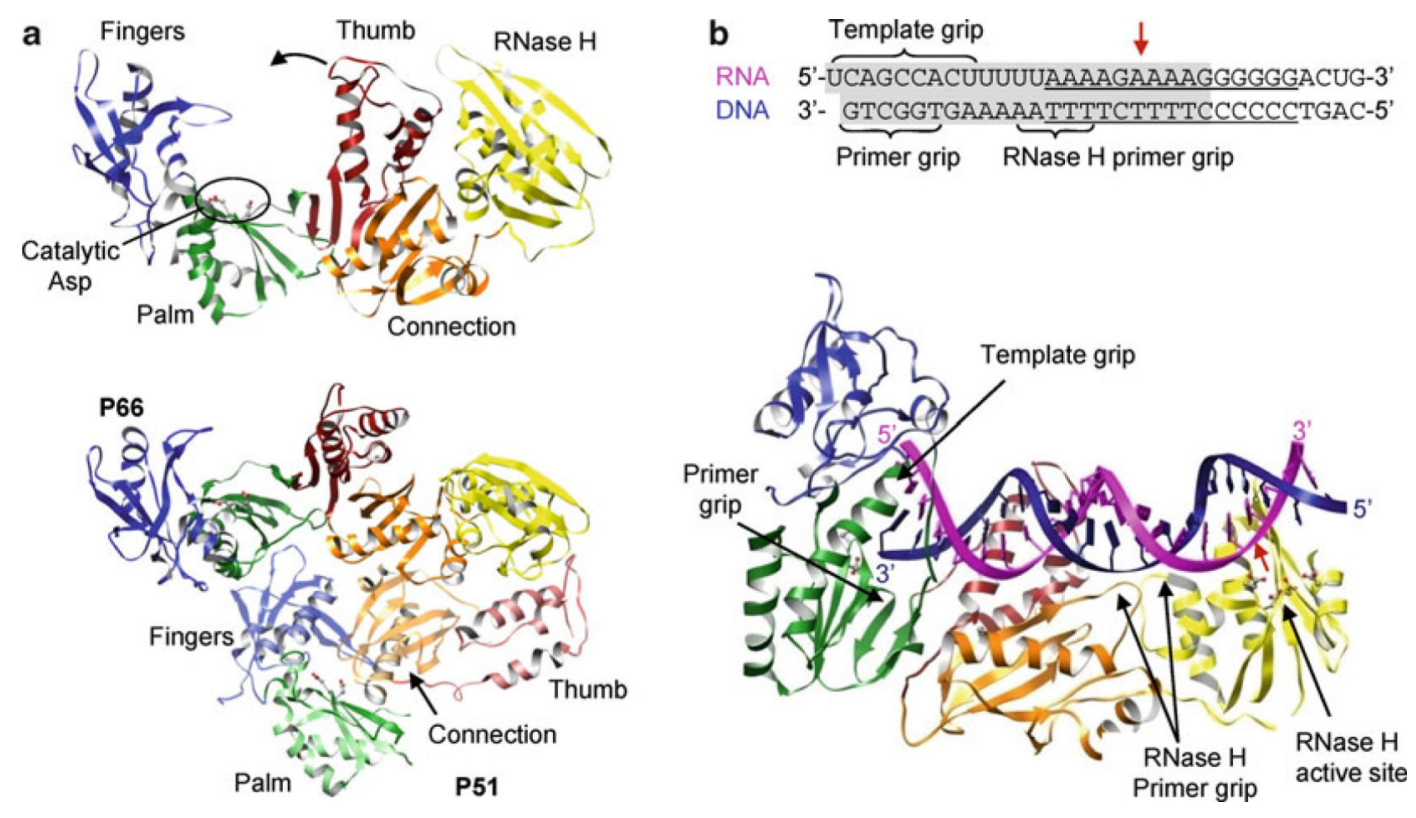

Fig. 12.11.

Structures of HIV reverse transcriptase. (a) p66 subunit (top) and p66-p51 heterodimer (bottom). The fingers (blue), palm (green), thumb (red), connection (orange), and RNase $\mathrm{H}$ (yellow) domains of p66 are in solid colors and domains of p51 are in transparent colors. Two aspartic residues in the YMDD motif (motif $\mathrm{C}$ ) are shown as ball-and-stick models. The polymerase is in an "open" conformation due to binding of substrate, which is omitted in the figure for clarity. Note the connecting domain in p51 is inserted between the palm and the thumb domains, making p51 inactive as a polymerase. (b) Structure of p66-p51 heterodimer complexed with a PPT-containing RNA-DNA hybrid. Only the p66 subunit is shown for clarity. The sequence of the RNA-DNA hybrid used in the crystallization is shown with the PPT underlined and the portion visible in the crystal structure shaded in gray (top). Template RNA and primer DNA are shown in magenta and blue, respectively, and the RNase $\mathrm{H}$ cleavage site is indicated with a red arrow. The primer grip, template grip, and RNase $\mathrm{H}$ primer grip are indicated 


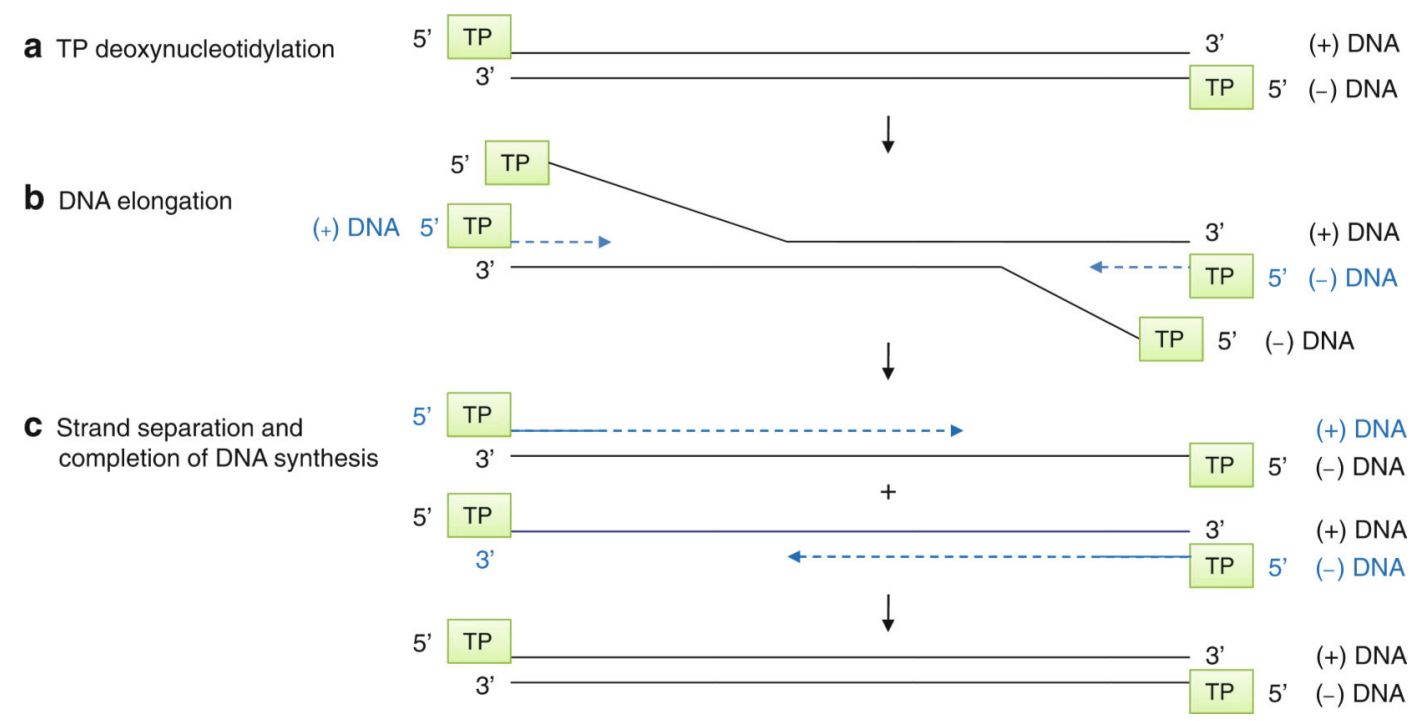

Fig. 12.12.

$\varphi 29$ protein-primed DNA replication. The linear dsDNA genome of $\varphi 29$ has a terminal protein (TP) attached at both $5^{\prime}$-ends. (a) TP deoxynucleotidylation. The $\varphi 29$ polymerase uses TP to initiate DNA synthesis from either end of the linear DNA genome. (b) DNA elongation. The intermediate contains a full-length dsDNA with one or more short ssDNA. (c) Strand separation and completion of DNA synthesis. When the two converging DNA polymerases merge, the templates become separated into two replication intermediates. Each of these consists of a full-length genome, one end of which is double-stranded and the other is single-stranded. Continuous DNA synthesis completes the replication of the $20-\mathrm{kb}$ DNA genome 


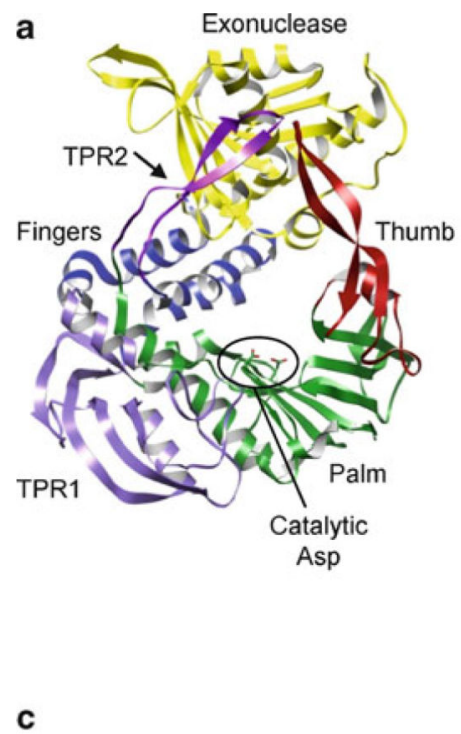

DNA template 5'-ACACGTAAGCAGTC-3' DNA primer 3'- CATTCGTCAG-5'

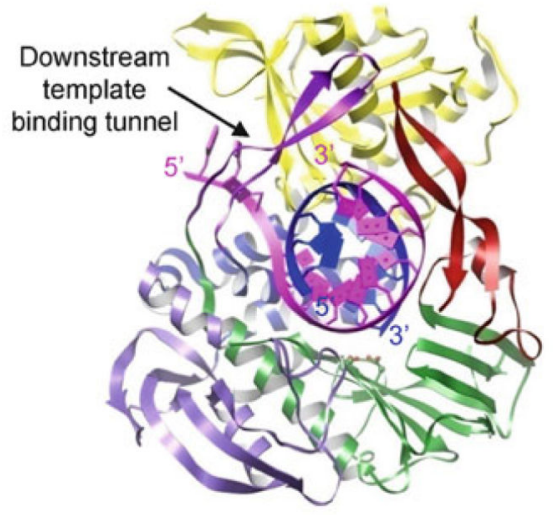

b

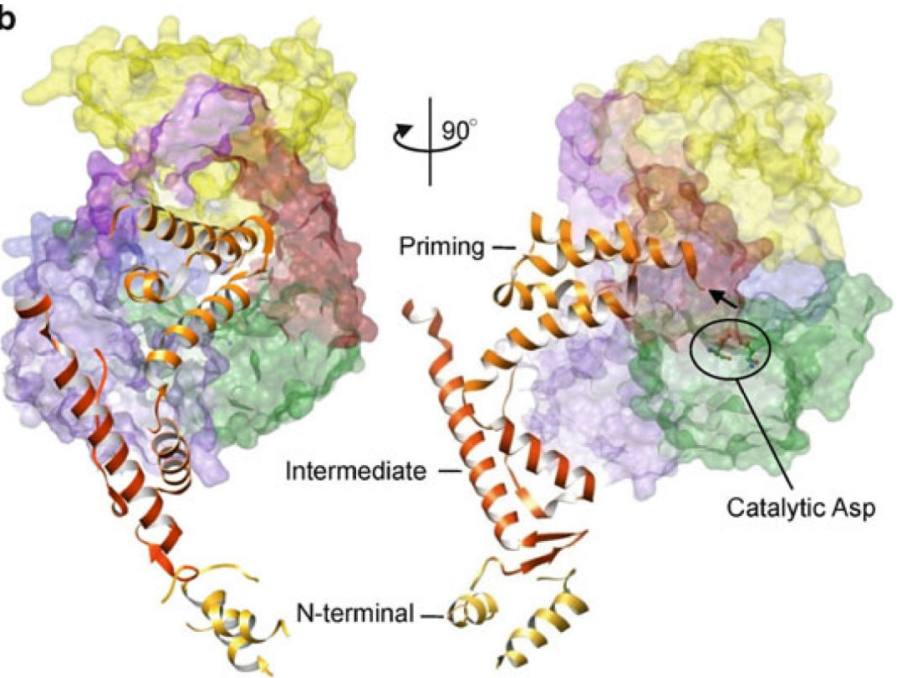

d
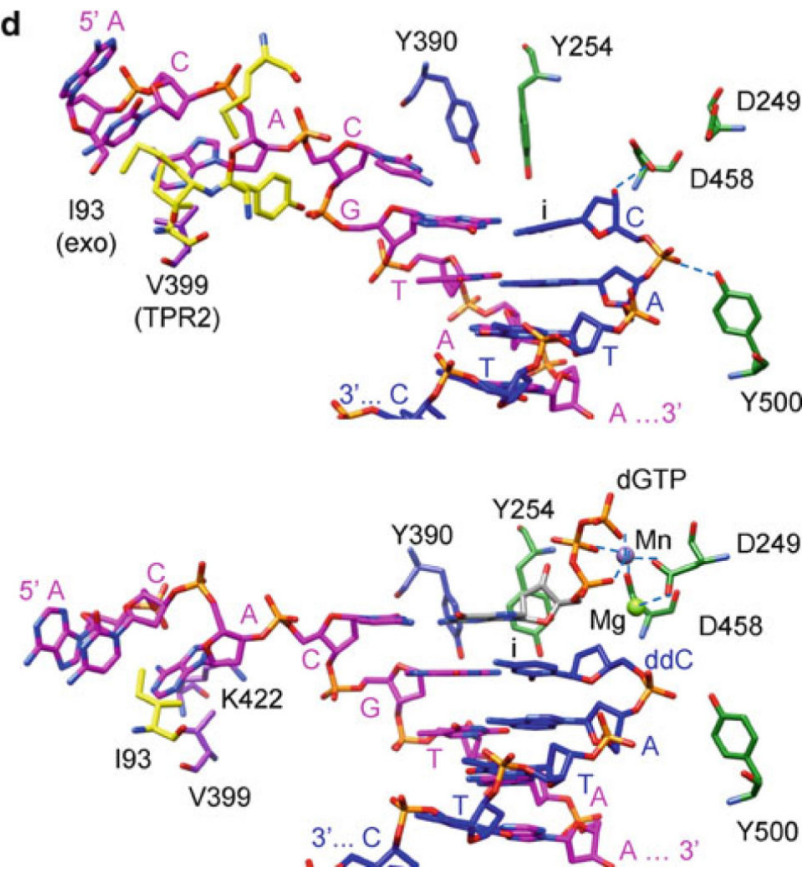

Fig. 12.13.

Structures of $\varphi 29$ DNA-dependent DNA polymerase. (a) $\varphi 29$ polymerase. The N-terminal exonuclease, fingers, palm, and thumb domains are shown in yellow, blue, green, and red, respectively. The TPR1 and TPR2 regions are shown in purple and magenta. Two catalytic Asp residues (Asp249 and Asp458) in the motifs A and C are shown as ball-and-stick models. (b) $\varphi 29$ polymerase-terminal protein (TP) heterodimer. The polymerase is shown as a transparent surface, and the TP is in ribbons. The N-terminal, intermediate, and priming domains of TP are labeled and shown in gold, dark orange, and light orange, respectively. The polymerase on the left is in a same orientation as in (a). (c) $\varphi 29$ polymerase complexed with template-primer. The template and primer strands are shown in magenta and blue. The sequences of template and primer strands are shown. Note that the $5^{\prime}$-end template is threaded under the downstream template-binding tunnel. (d) Active site in template-primer 
(top) and template-primer-NTP (bottom) complexes. The template-primer-NTP complex was trapped by incorporating a $2^{\prime}, 3^{\prime}$-dideoxynucleotide into the primer terminus and thus preventing a further nucleotidyl transfer reaction. The active site residues are colored according to their domains as in (a) 


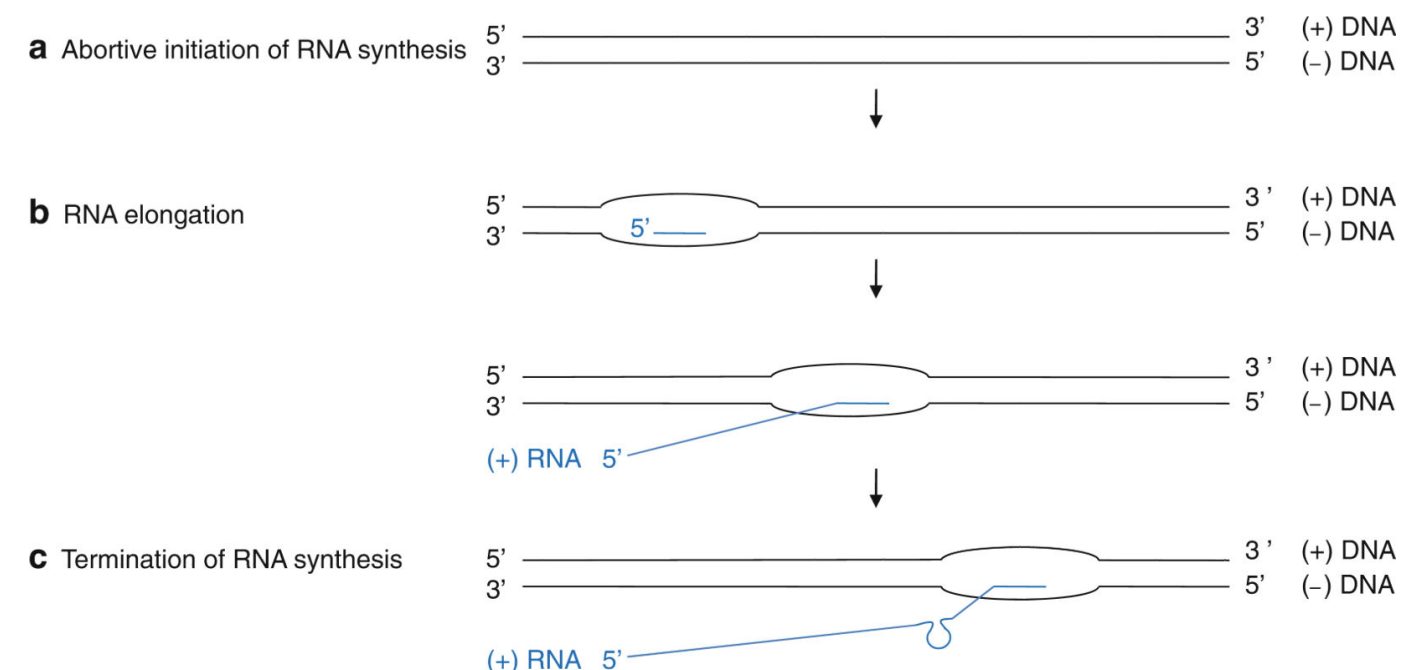

Fig. 12.14.

RNA transcription by T7 DNA-dependent RNA polymerase. (a) Initiation of RNA synthesis. The T7 RNA polymerase binds at the promoter site, separates the dsDNA genome, and initiates RNA transcription. The polymerase synthesizes short three- to eightnucleotide long RNA oligomers de novo that are released from the polymerase-promoter complex. Unlike the DNA replication seen in Fig. 12.11, only a small portion of dsDNA is separated to form a DNA-RNA hybrid (transcription bubble). Two DNA strands reanneal around the transcription bubble as the polymerase moves along the template. (b) RNA elongation. Once the RNA chain reaches about nine nucleotides, the polymerase elongates the RNA transcript with high processivity. (c) Termination. Once the polymerase encounters a termination signal, the polymerase and the RNA transcript are released from the nucleic acid 
a

b
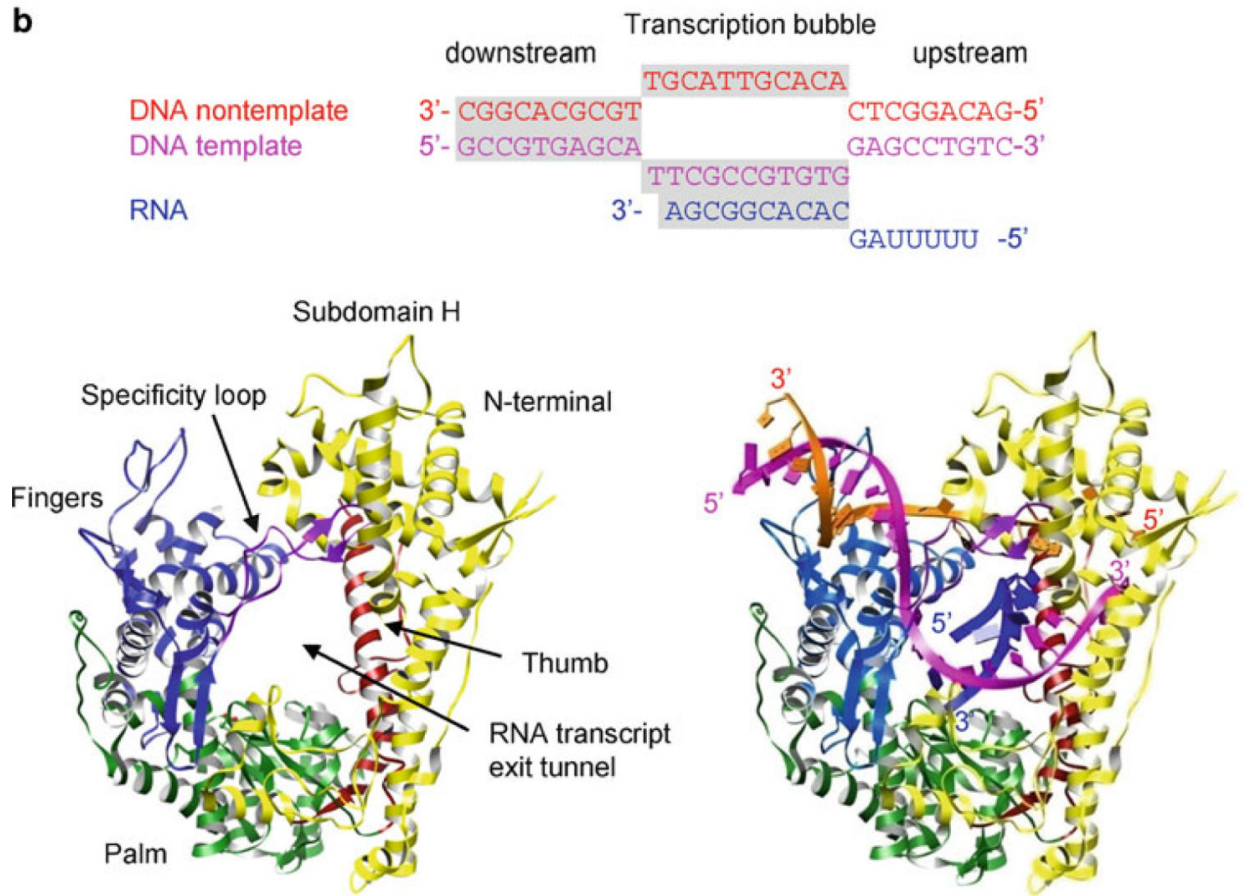

Fig. 12.15.

T7 RNA polymerase initiation and elongation complexes. (a) Initiation complex containing the promoter dsDNA and a three-nucleotide ssRNA transcript. The sequences of the nucleic acids are shown with the portions visible in the crystal structure shaded in gray (top). RNA synthesis starts at the +1 position. Polymerase is shown in the absence and presence of the bound nucleotides for clarity (bottom). The N-terminal domain, fingers, palm, and thumb domains are shown in yellow, blue, green, and red, respectively. The specificity loop in the fingers domain is shown in purple. The template (coding) strand, nontemplate strand, and 
the RNA transcript are shown in magenta, orange, and blue ribbons, respectively. (b) Elongation complex containing dsDNA and a ten-nucleotide RNA transcript. Note three nucleotides at the $5^{\prime}$-end of the RNA transcript are separated from the template and are exiting the active site 


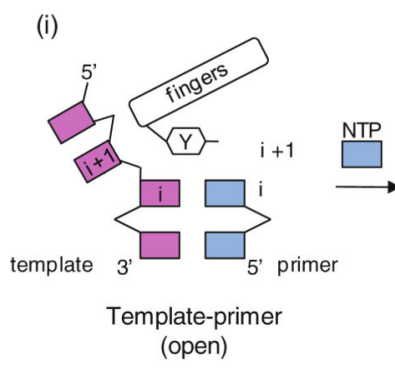

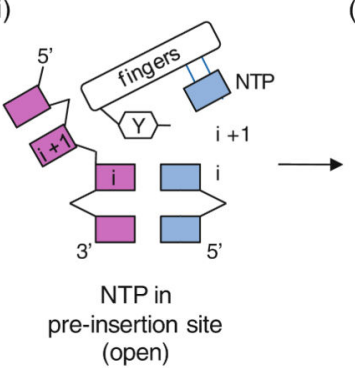

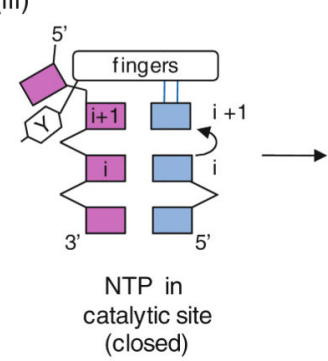

(iv)

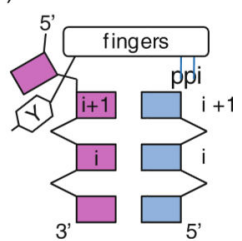

ppi (closed)

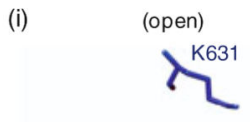

(ii)
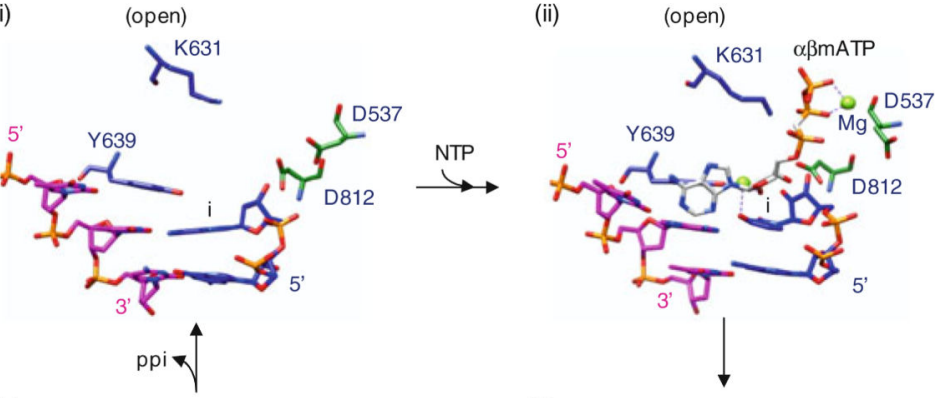

(iv)

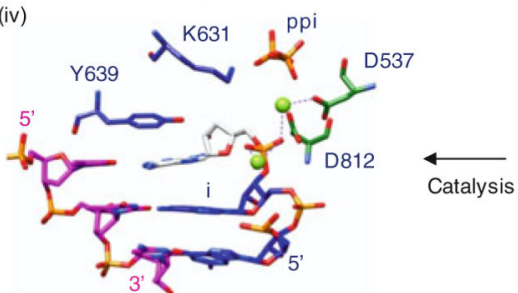

(closed)

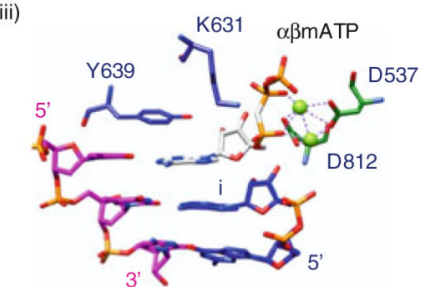

(closed)

Fig. 12.16.

Schematic of T7 polymerase reaction cycle (top) and structures of T7 RNA polymerase complexes in each step of the cycle (bottom). (i) Template-primer binding (posttranslocated state). DNA template (magenta) and RNA primer bind in the active site. Tyr639, shown as a hexagon, occupies the NTP binding site in the absence of incoming NTP. (ii) NTP binding the "pre-insertion" site. The incoming NTP binds in the pre-insertion site because the binding (insertion) site for NTP is partially occupied by Tyr639. The triphosphate of the incoming NTP interacts with residues in the fingers domain. (iii) Binding of the NTP in the catalytic site. Closing of the fingers domain onto the incoming NTP positions the NTP ideally for the nucleotidyl transfer reaction. (iv) Catalysis (pretranslocated state). Nucleotidyl transfer reaction occurs. Pyrophosphate (ppi) leaving group binds in the active site in the closed conformation of the fingers domain 